\title{
Study on the Parameter Equation of Coal and Gas Outburst Hole
}

\author{
Fei Wang $\mathbb{D}^{1,2}$ Yuzhong Yang $\mathbb{D},{ }^{1}$ Liyun $W u\left(\mathbb{D},{ }^{1}\right.$ Han Meng $\mathbb{D},{ }^{1}$ and Lei Peng ${ }^{1}$ \\ ${ }^{1}$ School of Energy Science and Engineering, Henan Polytechnic University, Jiaozuo 454003, China \\ ${ }^{2}$ Bureau of Emergency Management of Liupanshui, Liupanshui 553000, Guizhou, China \\ Correspondence should be addressed to Yuzhong Yang; jityyz@hpu.edu.cn
}

Received 7 January 2021; Revised 4 February 2021; Accepted 27 February 2021; Published 19 March 2021

Academic Editor: Gong-Da Wang

Copyright (c) 2021 Fei Wang et al. This is an open access article distributed under the Creative Commons Attribution License, which permits unrestricted use, distribution, and reproduction in any medium, provided the original work is properly cited.

Studying the parameters of a coal and gas hole (CGOH), such as the hole shape, hole size and volume, coal quantity of CGOH, coal throw distance, calculated hole density, and gas pressure, is helpful in revealing the coal and gas outburst mechanism. In this study, we found that there were close mathematical relationships between these parameters. A nonlinear composite function relationship (CGOH parameter equation) was observed between the coal quantity, $\mathrm{CGOH}$ volume, and throw distance. The correctness of these relationships was verified using the Origin software. The stagnation point and inflection point of the parameter curve were obtained through the derivation of the parameter equation, and the transformation path from coal and gas outburst to coal and gas extrusion or dumping was clarified. At the same time, the equations of gas pressure, coal quantity, and throw distance are derived.

\section{Introduction}

Coal and gas outburst (CGO) is a very serious dynamic phenomenon [1-3]. Many scholars have conducted research on coal and gas outbursts and unanimously agree with the hypothesis of the combined effect of coal and gas outbursts. Based on the comprehensive effect hypothesis, numerous scholars have carried out a series of CGO simulation experiments in the laboratory [4-10]. Cai et al. [11] first carried out a three-dimensional simulation test of CGO, using crushed and sieved compressed coal with a layer thickness of less than $0.1 \mathrm{~mm}$. Yan et al. [12] used different gases in CGO simulation tests, which proved that higher gas pressures and better adsorption/desorption capacities corresponded to higher outburst strength values. Several researchers conducted outburst simulation tests using self-designed CGO devices. Thus, Yin et al. [13, 14] performed the delayed outburst test of uncovering coal in rock cross cut. Xu et al. [15] carried out the CGO simulation test under different outburst calibers. Wang et al. [16] performed simulation tests of CGO under different gas pressures. Sobczyk [17] used different gases to carry out CGO simulation tests. He reported that $\mathrm{N}_{2}$ required a higher gas pressure than $\mathrm{CO}_{2}$ to cause CGO, while the duration of $\mathrm{CO}_{2}$ outburst was longer under the same gas pressure conditions. Yuan et al. [18] carried out a CGO simulation test with a self-designed device and reported that the CGO characteristics of soft coals were more pronounced than those of hard ones, the outburst strength was larger, and there was an obvious sorting phenomenon. Meanwhile, medium-hard coal was fractured into fragments of only high gas pressures, with no pronounced sorting phenomenon. However, the mechanical mechanism of coal and gas outburst still needs to be further studied.

When studying the CGO mechanism, researchers mainly focus on the shape of the coal and gas outburst hole (CGOH) and seldom study the parameters related to the hole and their relationships [19-29]. The various parameters of the CGOH (including the coal quantity, volume, calculated density, and throw distance) are to a certain response to the stress of the coal body and the energy of CGO. Starting from the CGO accidents that occurred in Yunnan Province, Guizhou Province, and Sichuan Province (i.e., YGC) of China, the $\mathrm{CGOH}$ parameters were obtained, sorted, selected, and analysed. Then, the most appropriate mathematical modelling method was selected using Matlab, Origin, SPSS, and other mathematical software. A mathematical model of the $\mathrm{CGOH}$ parameters was established, and the mathematical relationships between them were analysed in an attempt to reveal the CGO mechanism. 
The death toll of coal mine accidents in YGC ranks among the top of China's in 2019; from the perspective of the national coal production and casualties, Guizhou Province accounted for $18.98 \%$ of the casualties (60 people) with $3.46 \%$ of the output, Sichuan Province accounted for $12.025 \%$ of the casualties (38 people) with $0.87 \%$ of the output, and Yunnan Province accounted for $7.59 \%$ of the casualties (20 people) with $1.27 \%$ of the output. In comparison with the YGC, the Inner Mongolia Autonomous Region accounted for $27.6 \%$ of the output with only $2.85 \%$ of the casualties (9 people), as shown in Figure 1 and Table 1, published on the website of the Provincial Coal Mine Safety Supervision Bureau (the latest data for 2020 have not yet been released).

From the perspective of the severity and causes of coal mine accidents, YGC is the disaster area with major gas accidents in China; taking Liupanshui City (LPS) of Guizhou Province as an example, there are the following rules:

(1) LPS is prone to major coal mine accidents. From 2001-2019, there were 70 major coal mine accidents in Guizhou Province, with 1078 deaths (including 59 major gas accidents and 923 deaths). Among them, there were 18 major coal mine accidents with 301 deaths (accounting for $25.71 \%$ and $27.92 \%$ of the total number of major coal mine accidents in Guizhou Province) in LPS.

(2) The main cause of coal mine accidents in LPS is gas, and the gas accidents and CGO accidents both meet $60 \%$. Firstly, $60 \%$ of the casualties are caused by gas. From 1991 to 2020, 1083 coal mine accidents occurred with 2905 deaths in LPS, as shown in Figure 2 and Table 2, of which 1749 deaths (60.2\%) were caused by gas accidents. Secondly, $60 \%$ of gas accidents are CGO accidents. As shown in Figure 3, from 2010 to 2020, there were 23 gas accidents with 186 deaths in LPS, including 14 CGO accidents and 128 deaths, which account for $60.87 \%$ of the accidents and $68.82 \%$ of the casualties. Therefore, the study of CGO is necessary.

\section{Study of the CGOH Parameter Equation}

2.1. Correlation between Coal Quantity and Throw Distance. By sorting out and analysing the accident data for 93 outburst accidents in the YGC, 79 accident records were screened out, along with three groups of data of buried depth, CGO coal quantity, and throw distance, as listed in Table 3, and a 3D scatter diagram and its projection on three planes $(X Y, X Z, Y Z)$ are made, as shown in Figure 4. There may be linear correlation between coal quantity and throw distance, as shown by the black line on the $Y Z$ plane in Figure 4. But, there is no linear correlation between buried depth and coal quantity ( $X Y$ plane) or between buried depth and throw distance ( $X Z$ plane).

The degree of correlation between coal quantity and throw distance was further analysed using SPSS17.0 and origin 2019 to study the correlation degree of coal quantity and throw distance in 79 accidents, as shown in Table 4 and

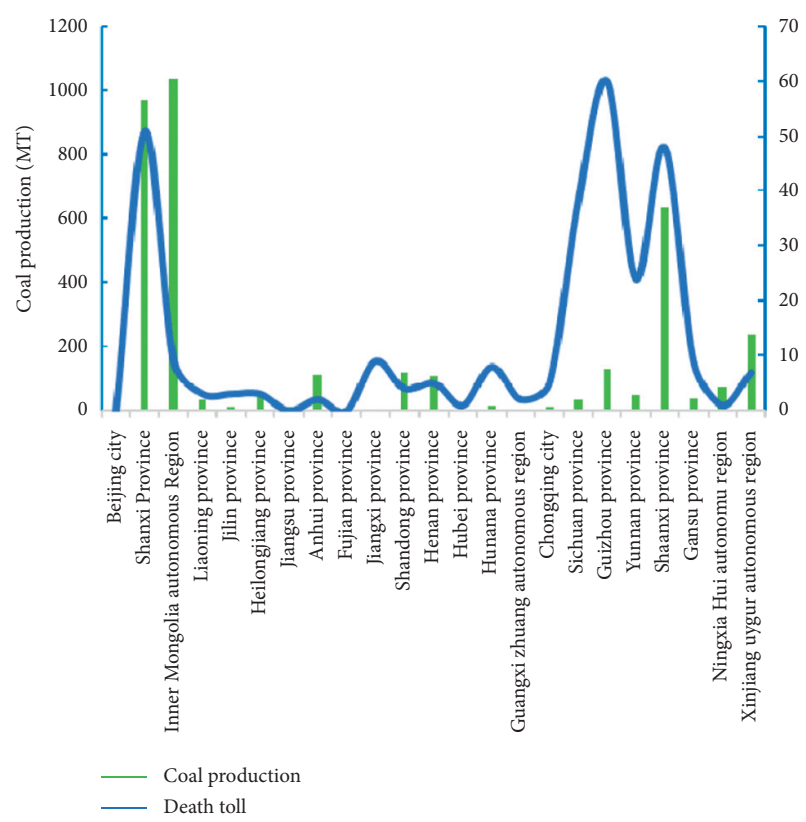

Figure 1: Coal production and death toll statistics for 23 provinces in 2019 .

Figure 5. Because the two sets of data for the throw distance and coal quantity did not fit a normal distribution, the Pearson correlation coefficient was not suitable for their correlation. However, the Spearman correlation coefficient (for two variables) or Kendall coefficient (for three variables) could be used. As listed in Table 4, the Spearman correlation coefficient was 0.821 , with a significance level of lesser than 0.05 , indicating that the positive correlation between the two was significant. However, although the $R$-square (COD) and the adj. $R$-square are 0.68145 and 0.66817 , respectively, the correlation is not very significant, which only indicates that they are monotonically correlated, as shown in Figure 5.

Therefore, it was determined that the coal quantity was positively related to the throw distance Figure 6 .

The relationship between throw distance and CGO coal quantity is not monotonic, but nonlinear, as shown in Figure 7: (1) with the increase in the amount of CGO coal quantity, the throw distance increases to the maximum value and then decreases. (2) When the amount of CGO coal quantity is the same, the throw distance of shallow buried depth is obviously larger than that of deep buried depth. (3) In the middle buried depth (about $300 \mathrm{~m}$ ), with the increase in the CGO coal quantity amount, the throw distance will have a short decline before reaching the maximum value, then increase to the maximum value, and then, decrease.

In order to further verify the conclusion of Figure 7, the data of 79 CGO accidents are matrixed and then logarithmically meshed, so as to make a 3D colormap surface, as shown in Figures 8 and 9, showing the same rule. The 3D colormap surface of buried depth, coal quantity, and throw distance (XYZ gridding) and a 3D colormap surface of buried depth, coal quantity, and throw distance (XYZ logarithmic gridding) are different representation types of the three colormap surfaces. 
TABle 1: Some gas accidents in YGC.

\begin{tabular}{|c|c|c|c|c|c|c|c|c|c|}
\hline Time & $\begin{array}{l}\text { Coal mine with } \\
\text { accident }\end{array}$ & Severity & $\begin{array}{c}\text { Death } \\
\text { toll }\end{array}$ & $\begin{array}{l}\text { Type of } \\
\text { accident }\end{array}$ & Time & $\begin{array}{l}\text { Coal mine with } \\
\text { accident }\end{array}$ & Severity & $\begin{array}{c}\text { Death } \\
\text { toll }\end{array}$ & $\begin{array}{l}\text { Type of } \\
\text { accident }\end{array}$ \\
\hline 2010.1 .26 & $\begin{array}{l}\text { Yushe coal mine } \\
\text { (Guizhou) }\end{array}$ & $\begin{array}{c}\text { Larger } \\
\text { accident }\end{array}$ & 5 & CGO & 2016.5 .3 & $\begin{array}{l}\text { Shaba coal mine } \\
\text { (Yunnan) }\end{array}$ & $\begin{array}{l}\text { Larger } \\
\text { accident }\end{array}$ & 6 & $\begin{array}{c}\text { Gas } \\
\text { explosion }\end{array}$ \\
\hline 2010.4 .5 & $\begin{array}{c}\text { Huachu coal mine } \\
\text { (Guizhou) }\end{array}$ & $\begin{array}{l}\text { Larger } \\
\text { accident }\end{array}$ & 5 & CGO & 2017.2.27 & $\begin{array}{c}\text { Dahebian coal mine } \\
\text { (Guizhou) }\end{array}$ & $\begin{array}{l}\text { Larger } \\
\text { accident }\end{array}$ & 9 & $\begin{array}{l}\text { Gas } \\
\text { explosion }\end{array}$ \\
\hline 2011.8.4 & $\begin{array}{l}\text { Guohekou coal } \\
\text { mine (Guizhou) }\end{array}$ & $\begin{array}{c}\text { Major } \\
\text { accident }\end{array}$ & 10 & $\begin{array}{c}\text { Gas } \\
\text { explosion }\end{array}$ & 2018.8.6 & $\begin{array}{l}\text { Zimujia coal mine } \\
\text { (Guizhou) }\end{array}$ & $\begin{array}{c}\text { Major } \\
\text { accident }\end{array}$ & 13 & CGO \\
\hline 2011.3.21 & $\begin{array}{l}\text { Gold and silver } \\
\text { mine (Guizhou) }\end{array}$ & $\begin{array}{l}\text { Major } \\
\text { accident }\end{array}$ & 19 & $\begin{array}{l}\text { Gas } \\
\text { explosion }\end{array}$ & 2018.10 .18 & $\begin{array}{l}\text { Huanyuan coal mine } \\
\text { (Sichuan) }\end{array}$ & $\begin{array}{l}\text { Ordinary } \\
\text { accident }\end{array}$ & 2 & CGO \\
\hline 2012.11 .24 & $\begin{array}{l}\text { Xiangshui coal } \\
\text { mine (Guizhou) }\end{array}$ & $\begin{array}{l}\text { Major } \\
\text { accident }\end{array}$ & 23 & CGO & 2018.10 .25 & $\begin{array}{l}\text { Eagle rock well } \\
\text { (Sichuan) }\end{array}$ & $\begin{array}{l}\text { Larger } \\
\text { accident }\end{array}$ & 4 & $\begin{array}{c}\text { Gas } \\
\text { accident }\end{array}$ \\
\hline 2013.1.18 & $\begin{array}{l}\text { Jinjia coal mine } \\
\text { (Guizhou) }\end{array}$ & $\begin{array}{l}\text { Major } \\
\text { accident }\end{array}$ & 13 & CGO & 2019.4.3 & $\begin{array}{l}\text { Zaowei coal mine } \\
\text { (Yunnan) }\end{array}$ & $\begin{array}{l}\text { Ordinary } \\
\text { accident }\end{array}$ & 2 & $\begin{array}{l}\text { Gas } \\
\text { explosion }\end{array}$ \\
\hline 2013.3.12 & $\begin{array}{l}\text { Machang coal } \\
\text { mine (Guizhou) }\end{array}$ & $\begin{array}{l}\text { Major } \\
\text { accident }\end{array}$ & 25 & CGO & 2019.4.25 & $\begin{array}{l}\text { Sanjin coal mine } \\
\text { (Yunnan) }\end{array}$ & $\begin{array}{l}\text { Larger } \\
\text { accident }\end{array}$ & 4 & CGO \\
\hline 2013.11 .2 & $\begin{array}{l}\text { Dahaizi coal mine } \\
\text { (Yunnan) }\end{array}$ & $\begin{array}{l}\text { Ordinary } \\
\text { accident }\end{array}$ & 3 & $\begin{array}{l}\text { Gas } \\
\text { explosion }\end{array}$ & 2019.6 .5 & $\begin{array}{l}\text { 1\# mine of Tianhong } \\
\text { mining salt } \\
\text { (Chongqing) }\end{array}$ & $\begin{array}{l}\text { Ordinary } \\
\text { accident }\end{array}$ & 1 & CGO \\
\hline 2013.12 .13 & $\begin{array}{l}\text { Bailongshan coal } \\
\text { mine 1\# (Yunnan) }\end{array}$ & $\begin{array}{l}\text { Larger } \\
\text { accident }\end{array}$ & 9 & CGO & 2019.7 .28 & $\begin{array}{l}\text { Houxin coal mine } \\
\text { (Sichuan) }\end{array}$ & $\begin{array}{l}\text { Larger } \\
\text { accident }\end{array}$ & 3 & $\begin{array}{c}\text { Gas } \\
\text { explosion }\end{array}$ \\
\hline 2014.4.18 & $\begin{array}{l}\text { Wantian coal } \\
\text { mine (Guizhou) }\end{array}$ & $\begin{array}{l}\text { Larger } \\
\text { accident }\end{array}$ & 7 & CGO & 2019.7.29 & Longwo (Guizhou) & $\begin{array}{l}\text { Larger } \\
\text { accident }\end{array}$ & 4 & CGO \\
\hline 2014.4.21 & $\begin{array}{l}\text { Lateritic coal } \\
\text { mine (Yunnan) }\end{array}$ & $\begin{array}{l}\text { Major } \\
\text { accident }\end{array}$ & 14 & $\begin{array}{c}\text { Gas } \\
\text { explosion }\end{array}$ & 2019.7.31 & $\begin{array}{l}\text { Dashu coal mine } \\
\text { (Guizhou) }\end{array}$ & $\begin{array}{l}\text { Larger } \\
\text { accident }\end{array}$ & 7 & $\begin{array}{c}\text { Gas } \\
\text { explosion }\end{array}$ \\
\hline 2014.5.21 & $\begin{array}{l}\text { Caoba coal mine } \\
\text { (Yunnan) }\end{array}$ & $\begin{array}{l}\text { Larger } \\
\text { accident }\end{array}$ & 5 & $\begin{array}{l}\text { Gas } \\
\text { explosion }\end{array}$ & 2019.9.22 & $\begin{array}{l}\text { Goutou coal mine } \\
\text { (Yunnan) }\end{array}$ & $\begin{array}{l}\text { Ordinary } \\
\text { accident }\end{array}$ & 1 & $\begin{array}{l}\text { Gas } \\
\text { explosion }\end{array}$ \\
\hline 2014.5.25 & $\begin{array}{l}\text { Yushe coal mine } \\
\text { (Guizhou) }\end{array}$ & $\begin{array}{l}\text { Larger } \\
\text { accident }\end{array}$ & 8 & CGO & 2019.10.19 & $\begin{array}{l}\text { Guanyinshan coal } \\
\text { mine (Yunnan) }\end{array}$ & $\begin{array}{l}\text { Ordinary } \\
\text { accident }\end{array}$ & 2 & CGO \\
\hline 2014.6.11 & $\begin{array}{l}\text { Xinhua coal mine } \\
\text { (Guizhou) }\end{array}$ & $\begin{array}{l}\text { Major } \\
\text { accident }\end{array}$ & 10 & CGO & 2019.11.25 & $\begin{array}{l}\text { Sanjia coal min } \\
\quad \text { (Guizhou) }\end{array}$ & $\begin{array}{l}\text { Larger } \\
\text { accident }\end{array}$ & 2 & CGO \\
\hline 2014.11 .27 & $\begin{array}{l}\text { Songlin coal mine } \\
\text { (Guizhou) }\end{array}$ & $\begin{array}{l}\text { Major } \\
\text { accident }\end{array}$ & 11 & $\begin{array}{c}\text { Gas } \\
\text { explosion }\end{array}$ & 2019.12 .16 & $\begin{array}{c}\text { Guanglong coal min } \\
\text { (Guizhou) }\end{array}$ & $\begin{array}{l}\text { Major } \\
\text { accident }\end{array}$ & 16 & CGO \\
\hline
\end{tabular}

Ordinary accident $<3,3 \leq$ larger accident $<10,10 \leq$ major accident $<30,30 \leq$ especially major accident.

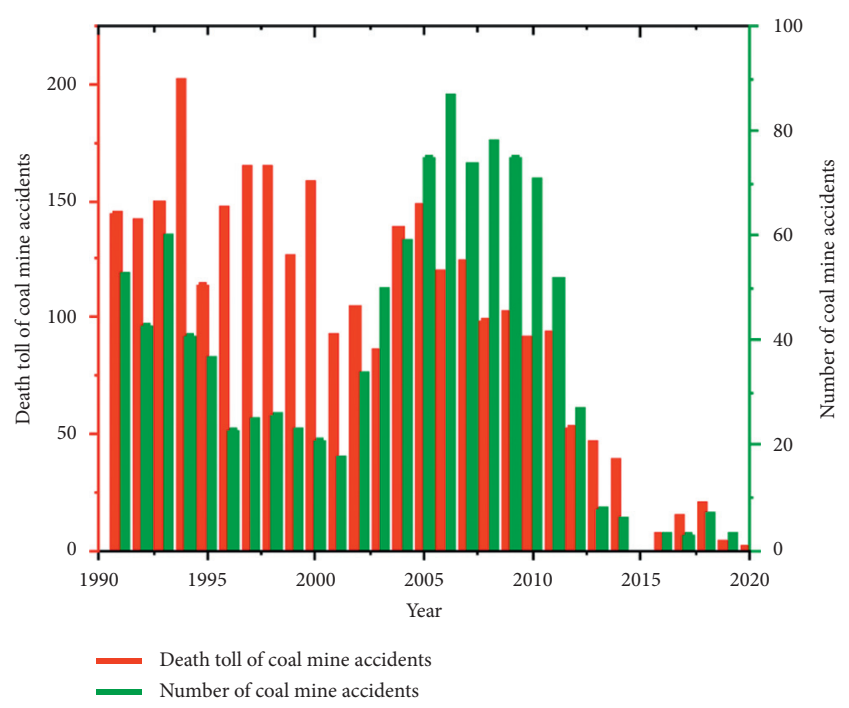

FIGURE 2: Number and death toll of coal mine accidents in LPS for 1990-2020.

2.2. Correlations between Calculated Density of $\mathrm{CGOH}$ and Throw Distance. Fifteen CGO accidents were recorded along with the detailed hole volume, coal quantity, and throw distance from 79 CGO accidents, as shown in Table 5 and Figure 10. Because each $\mathrm{CGOH}$ was an ellipsoid [30], its $\mathrm{CGOH}$ density was calculated as follows:

$$
\text { CGOH density }(\rho)=\frac{\text { Coal quantity }}{\text { CGOH Volume }}=\frac{m}{v} \text {. }
$$

As shown in Figure 10, two points (No. 35 and 36) with obvious deviations from the rest of the 15 points and two points (No. 31 and 41) without throw distance were removed, and the calculated density exhibited a certain nonlinear relationship with the throw distance.

\subsubsection{Research on the Mathematical Model of Correlation} between the Calculated Density of $\mathrm{CGOH}$ and Throw Distance. A mathematical model was established for the nonlinear relationship between the calculated density of $\mathrm{CGOH}$ and the throw distance. The hypothesis $\longrightarrow$ solution $\longrightarrow$ verification idea was adopted.

First, the noncumulative probability density curve of a chi square distribution was introduced, and Excel was used to produce the correlation curve, as shown in Figure 11. The probability function of the chi square distribution is represented as 
TABLE 2: Five years's trend statistics of death toll of gas accident in LPS (1991-2020).

\begin{tabular}{lccc}
\hline Year & Death toll of gas accident & Total number of deaths in coal mine accidents & Percentage \\
\hline $1991-1995$ & 501 & 753 & 0.66 \\
$1996-2000$ & 712 & 762 & 0.93 \\
$2001-2005$ & 282 & 538 & 0.49 \\
$2006-2010$ & 93 & 233 & 0.17 \\
$2011-2015$ & 137 & 48 & 0.59 \\
$2016-2020$ & 24 & 0.5 \\
\hline
\end{tabular}

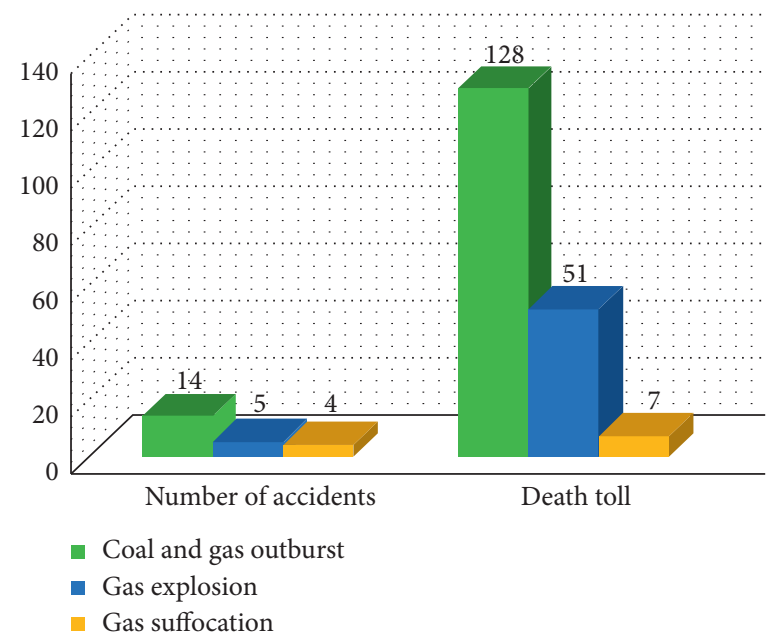

FIgURE 3: Coal mine accidents and deaths from gas outburst, gas explosion, and gas suffocation in LPS for 2010-2020.

$$
f(x)= \begin{cases}\frac{1}{2^{n} \Gamma(n / 2)} x^{(n / 2)-1} e^{(-x / 2)}, & x>0, \\ 0, & x \leq 0 .\end{cases}
$$

When $n=4$,

$$
f(x)= \begin{cases}\frac{1}{4} x \mathrm{e}^{-(x / 2)}, x>0 \\ 0, & x \leq 0\end{cases}
$$

Figures 10 and 11 are significantly similar. Therefore, it is advisable to assume that the calculated density and throw distance meet compound equation (4), and then, the correctness of the hypothesis is verified.

$$
y=C \cdot x \cdot e^{-D \cdot x}
$$

2.2.2. Mathematical Model Solution. For the convenience of modelling, 4 points (No. 19, 35, 36, and 61) were removed from the 15 points, along with 2 points (No. 31 and 41) without throw distance. As shown in Figure 12, a scatter diagram of the remaining 9 points was created using the Matlab software. Because of the nonlinear nature of the curve, the data for these 9 points are first transformed linearly [31], as shown in Table 6 and Figure 13, and the transformation process is shown in (5) and (6). The points $\left(x_{9}, y_{9}\right)$ for accident no. 2 showed extreme deviation and were eliminated, the remaining 8 points were fitted, and parameter equation (6) was finally obtained.

$$
y=C \cdot x \cdot e^{-D \cdot x} \Longrightarrow \frac{y}{x}
$$

$$
=C \cdot x \cdot e^{-D \cdot x} \Longrightarrow \ln \left(\frac{y}{x}\right)=\ln C-D \cdot x,
$$

2.2.3. Verification of the Mathematical Model. As shown in Figure 14, using the custom function compilation function of ORIGIN 2019 Pro, the new function $y=a^{*} x^{*}\left(\exp \left(-\mathrm{B}^{*}\right.\right.$ $x)$ ) was edited, the initial values of $a$ and $b$ were entered ( $a=28.8324071, b=0.065)$, and the coordinates of the points were obtained. After the ORIGIN 2019 Pro compiler (compile) verification was complete (Compile Done!), the function is called after storage. As shown in Figure 15, the line point graph of the 9 points was compared with the fitting 


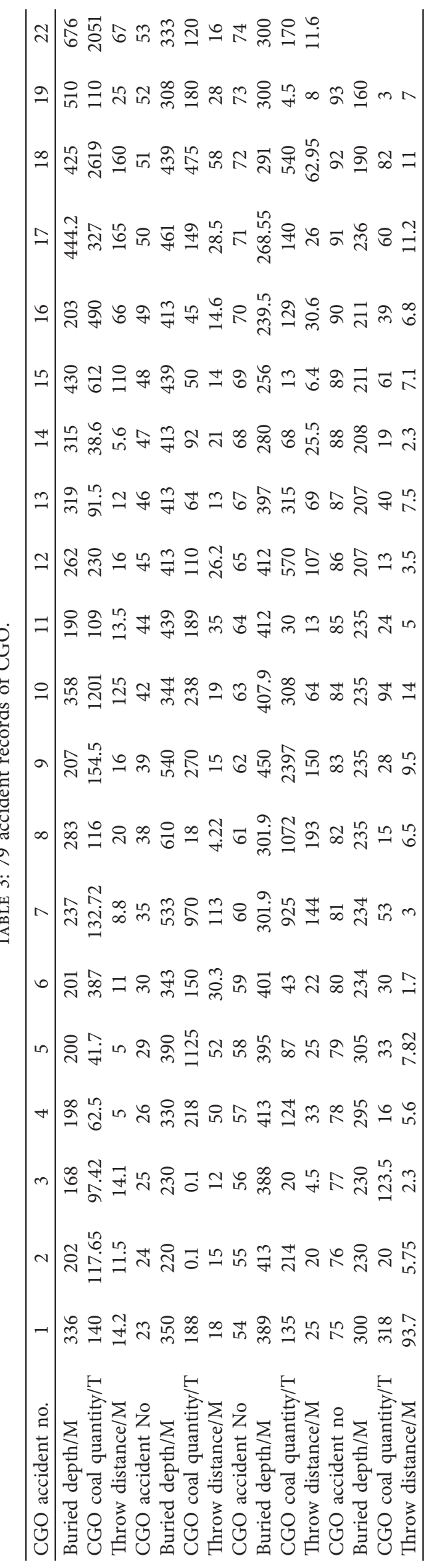




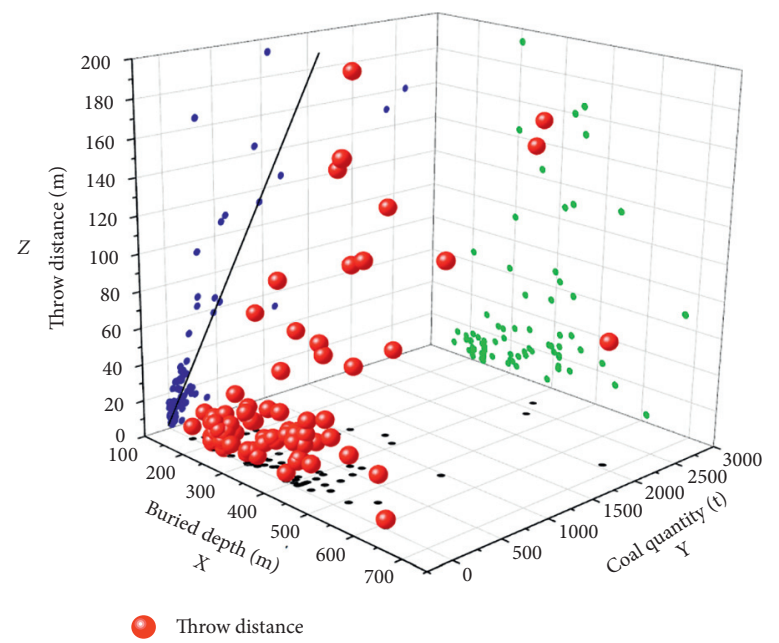

FIGURE 4: 3D scatter diagram of buried depth, coal volume, and throwing distance and its projection on three planes.

TABLE 4: Correlation between CGO coal quantity and throw distance.

\begin{tabular}{lccc}
\hline Array & Spearman's rho & CGO coal quantity & Throw distance \\
\hline \multirow{3}{*}{ CGO coal quantity } & Correlation coefficient & 1.000 & $0.821^{* *}$ \\
& Sig. (bilateral) & - & 0.000 \\
79 & 1.000 \\
Throw distance & $N$ & $0.821^{* *}$ & - \\
& Correlation coefficient & 0.000 & 79 \\
\hline
\end{tabular}

** When the confidence (double test) is 0.01 , the correlation is significant.

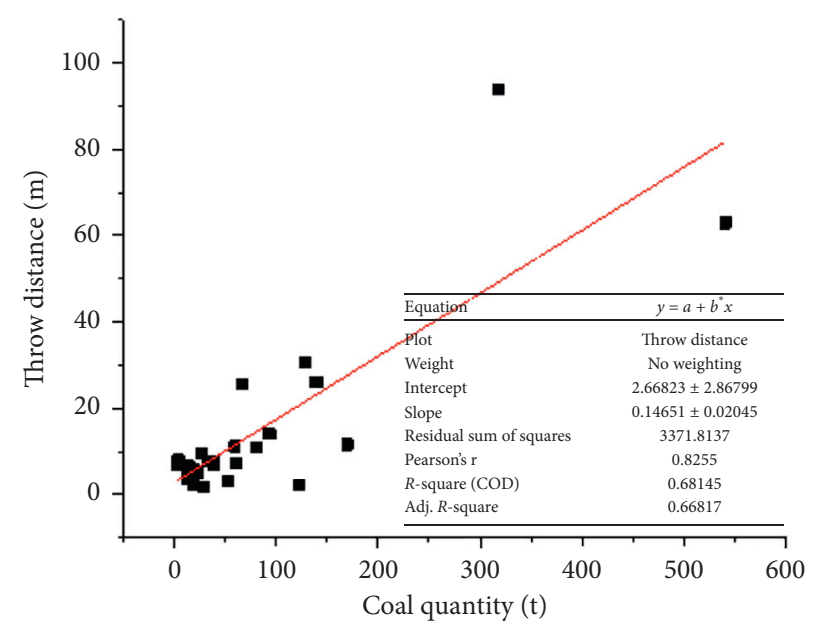

Figure 5: Linear correlation between CGO coal quantity and throw distance in 79 CGO accident.

graph of the compiled new function, and their fitting degree was as high as 0.9064 . The correctness of parameter equation (7) of the mathematical model was proven.

\subsection{Relationships between Parameters of $\mathrm{CGOH}$}

2.3.1. Parameter Equation of Protruding Hole. The parameter equation for calculated density and throw distance of $\mathrm{CGOH}$ is

$$
\begin{aligned}
& d=C \cdot x \cdot e^{-D \cdot x}, \\
& x=\frac{m}{v}=\frac{\text { outburst coal quantity }}{\text { volume of coal and gas outburst hole }} .
\end{aligned}
$$

Therefore, the parameter equation of $\mathrm{CGOH}$ is

$$
d=C \cdot \frac{m}{y} \cdot e^{-D \cdot m / v}
$$




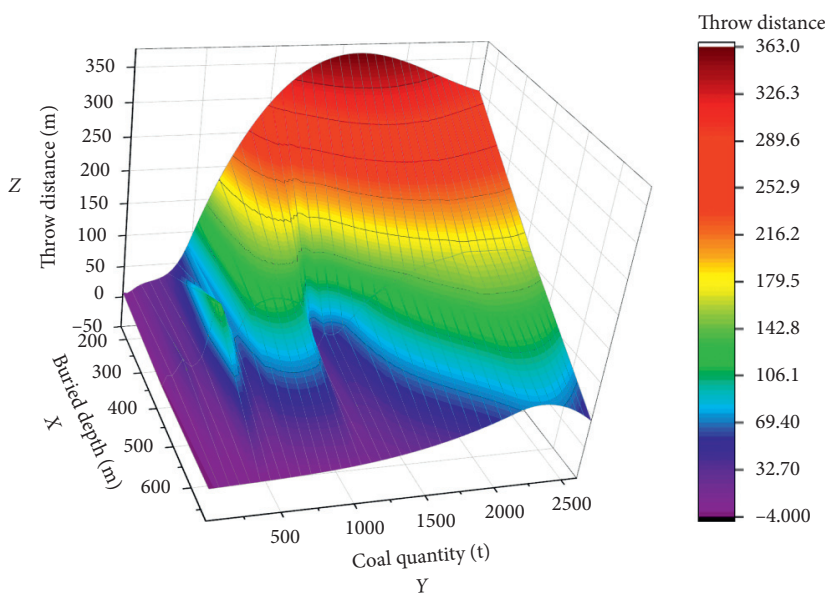

FiguRE 6: 3D colormap surface of buried depth, coal quantity, and throw distance (XYZ gridding).

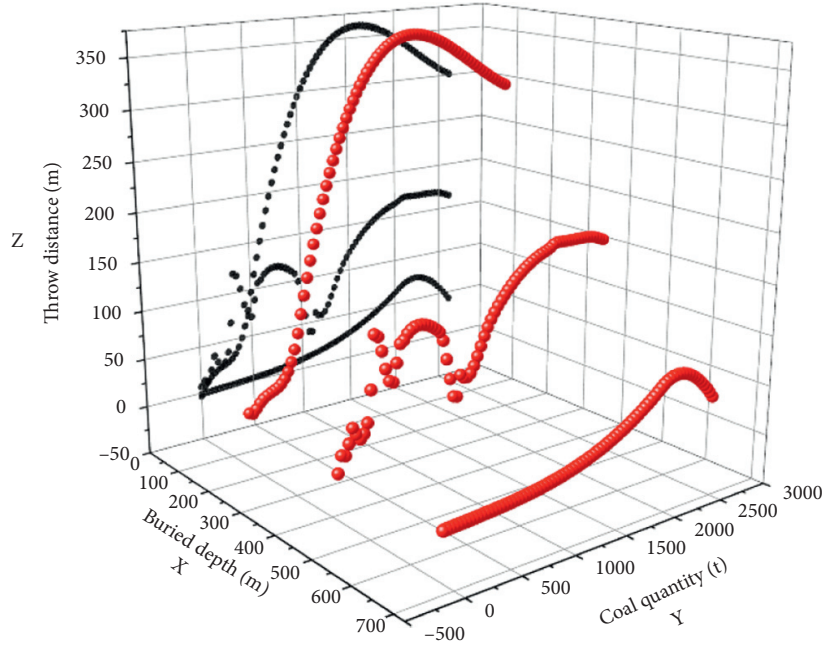

Figure 7: 3D matrix scatter diagram of buried depth, coal quantity, and throw distance and its projection on the YZ plane.

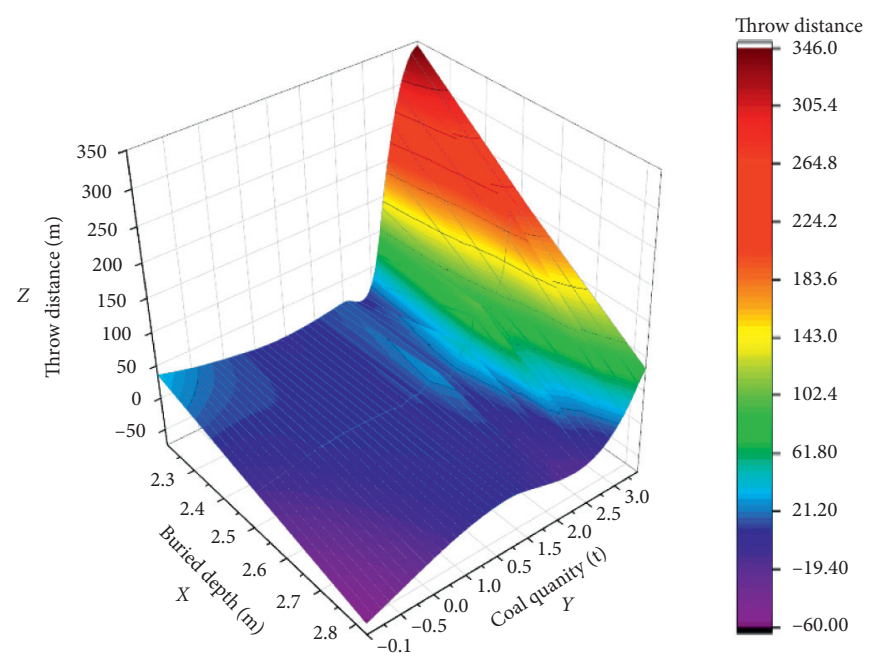

FigURE 8: 3D colormap surface of buried depth, coal quantity, and throw distance (XYZ log gridding). 
TABle 5: Parameters for 15 CGOH.

\begin{tabular}{lcccc}
\hline Accident no. & Hole volume $\left(\mathrm{m}^{3}\right)$ & Coal quantity $(t)$ & Calculated density $\left(\mathrm{m}^{3} / t\right)$ & Throw distance $(\mathrm{m})$ \\
\hline 2 & 0.31 & 117.7 & 379.68 & 11.5 \\
17 & 17.415 & 327 & 18.68 & 165 \\
18 & 342.7 & 2619 & 1.64 & 160 \\
19 & 8.7 & 110 & 3.64 & 25 \\
26 & 55.5 & 218 & 0.75 & 30 \\
30 & 201.06 & 150 & 58.82 & - \\
31 & 3.06 & 180 & 79.84 & 113 \\
35 & 12.15 & 970 & 4.77 & 7 \\
36 & 12.57 & 60 & 13.04 & -72.78 \\
41 & 6.28 & 81.9 & 60.19 & 19 \\
42 & 3.27 & 238 & 245.87 & 35 \\
44 & 3.14 & 189 & 43.56 & 64 \\
61 & 4.36 & 1072 & 49 & 62.95 \\
72 & 7.07 & 308 & & \\
\hline
\end{tabular}

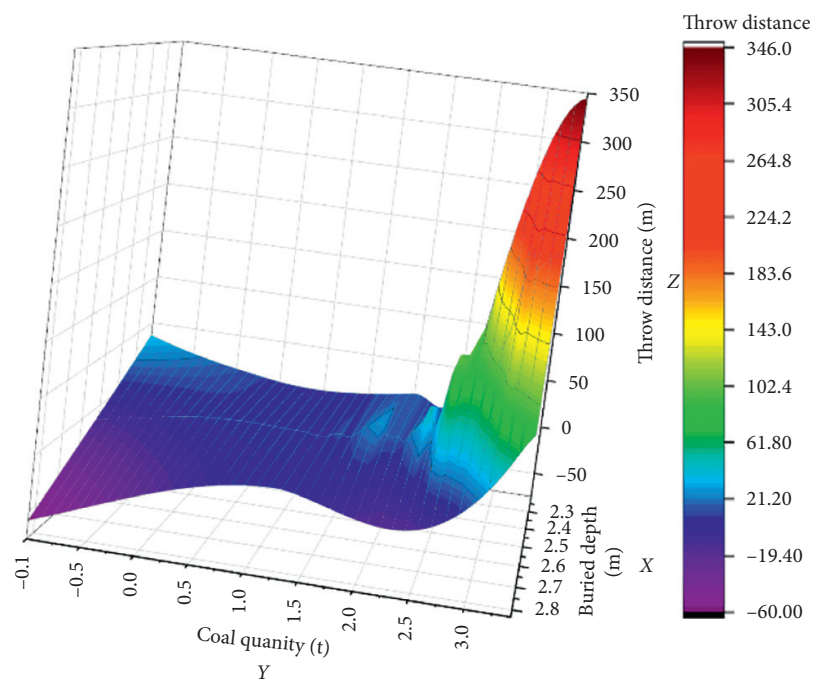

FIgURE 9: 3D colormap surface of buried depth, coal quantity, and throw distance (XYZ log gridding).

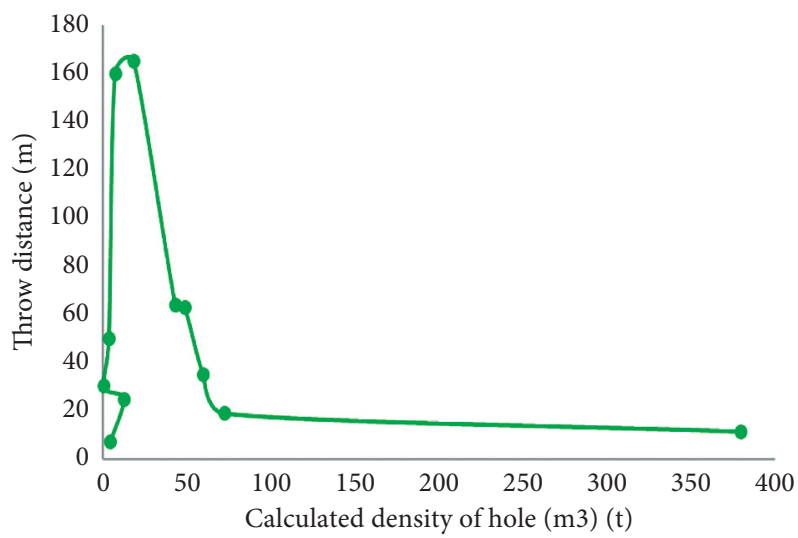

Figure 10: Point line diagram of the calculated density and throw distance. 


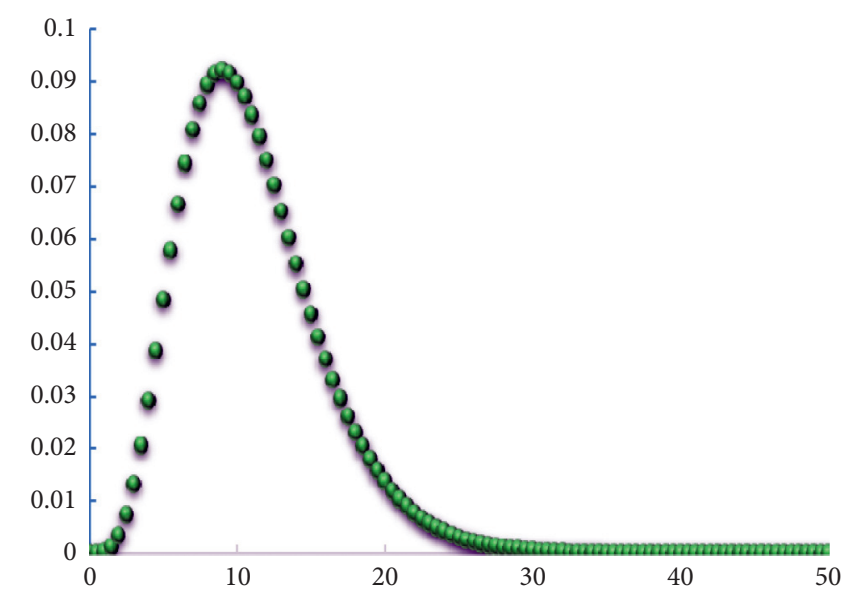

Figure 11: Probability density curve of chi square distribution not accumulating.

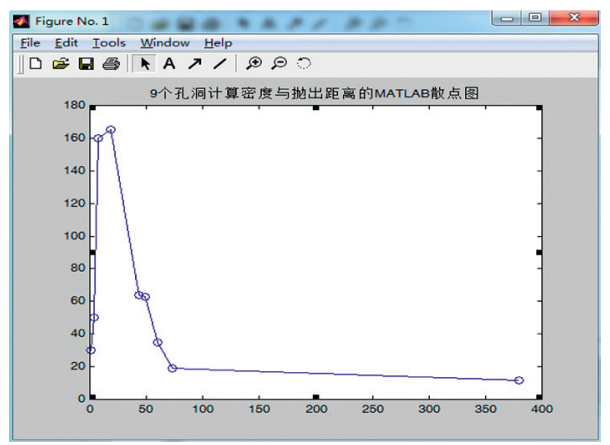

FIgURe 12: Matlab point line diagram of 9 points.

TABLE 6: Linear transformation.

\begin{tabular}{|c|c|c|c|c|c|c|c|c|c|c|}
\hline Category & Variables & $\left(x_{1}, y_{1}\right)$ & $\left(x_{2}, y_{2}\right)$ & $\left(x_{3}, y_{3}\right)$ & $\left(x_{4}, y_{4}\right)$ & $\left(x_{5}, y_{5}\right)$ & $\left(x_{6}, y_{6}\right)$ & $\left(x_{7}, y_{7}\right)$ & $\left(x_{8}, y_{8}\right)$ & $\left(x_{9}, y_{9}\right)$ \\
\hline \multirow{2}{*}{ Raw data } & $x$ & 0.75 & 3.93 & 7.64 & 18.68 & 43.56 & 49 & 60.19 & 72.78 & 379.68 \\
\hline & $y$ & 30.3 & 50 & 160 & 165 & 64 & 62.95 & 35 & 19 & 11.5 \\
\hline $\begin{array}{l}\text { Transformation } \\
\text { one }\end{array}$ & $y / x$ & 40.4 & 2.722646 & 20.942408 & 8.8329765 & 1.4692378 & 1.2846939 & 0.5814919 & .2610607 & 0.3028864 \\
\hline $\begin{array}{l}\text { Transformation } \\
\text { two }\end{array}$ & $\ln (y / x)$ & 3.6988298 & 2.5433836 & 3.0417762 & 2.178492 & 0.3847438 & 0.2505205 & -0.542158 & -1.343002 & -1.194397 \\
\hline New definition $x$ & $\begin{array}{c}X=x \\
Y=\ln (\gamma)\end{array}$ & $\begin{array}{r}0.75 \\
69882\end{array}$ & $\begin{array}{c}3.93 \\
54338\end{array}$ & $\begin{array}{c}7.64 \\
3.041776\end{array}$ & $\begin{array}{l}18.68 \\
178492\end{array}$ & $\begin{array}{r}43.56 \\
0384743\end{array}$ & $\begin{array}{c}49 \\
025052\end{array}$ & $\begin{array}{r}60.19 \\
-0.54215\end{array}$ & $\begin{array}{c}72.78 \\
-1343002\end{array}$ & $\begin{array}{c}379.68 \\
-1194397\end{array}$ \\
\hline
\end{tabular}

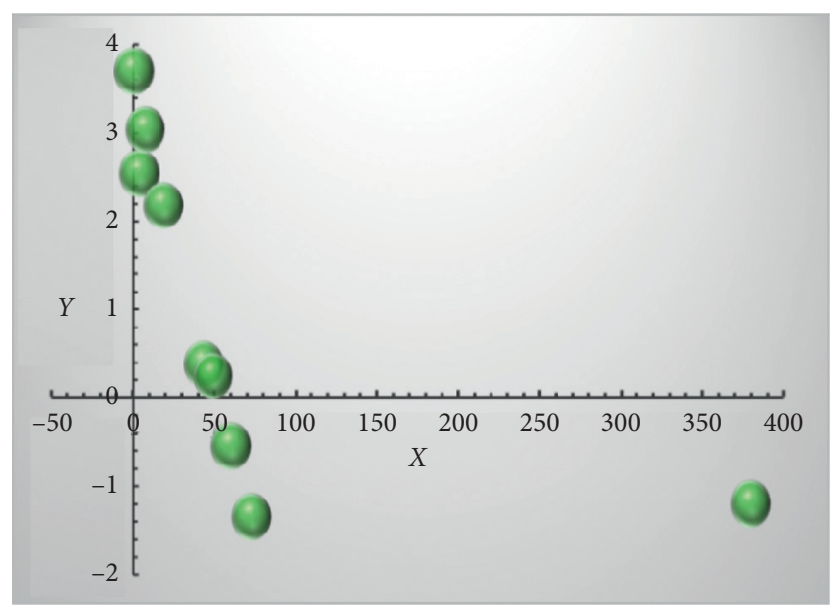

FIGURE 13: Scatter diagram after linearization of 9 points. 


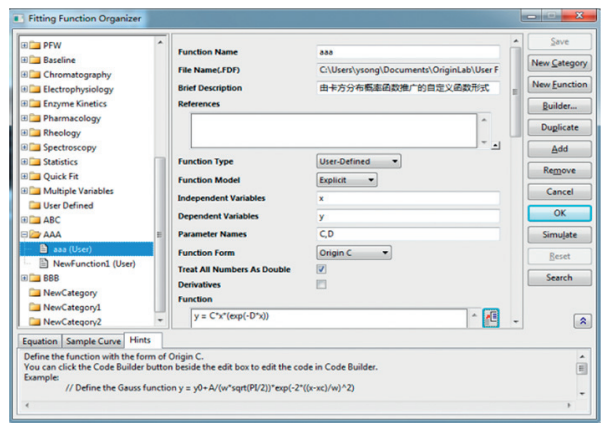

FIGURE 14: Origin software used to verify reliability of the mathematical model.

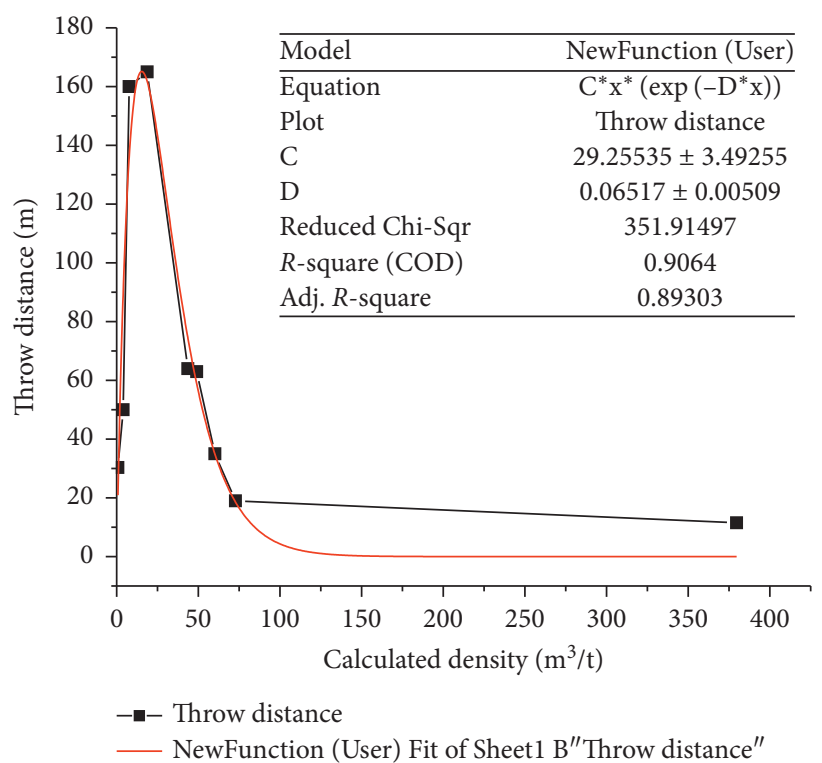

FIGURE 15: Origin software fitting verification.

where $d$ is the throw distance, $m$ is the $\mathrm{CGOH}$ coal quantity, and $v$ is the volume of $\mathrm{CGOH}$.

\subsubsection{Three-Dimensional Figure of $\mathrm{CGOH}$ Parameters. A} three-dimensional (i.e., 3D) scatter diagram of the coal quantity, hole volume, and throw distance (i.e., $\mathrm{CGOH}$ parameters) is shown in Figure 16. The 3D colormap surface is shown in Figure 17 (XYZ gridding) and 18 (XYZ Log Gridding). The 3D colormap surface and its nonlinear surface fitting (Gauss 2D) of CGOH parameters are shown in Figures 19 and 20, and the 3D colormap surface and its nonlinear surface fitting (Extreme Cum) of $\mathrm{CGOH}$ parameters are shown in Figures 21 and 22.

The $\mathrm{CGOH}$ volume, coal quantity, and throw distance do satisfy the nonlinear relationship, as shown in Figures 16 and 17.

The specific relationship is shown in Figures 22 and 19, with the following rules: (1) When the volume of CGOH is less than 20 or more than $300 \mathrm{~m}^{3}$, the throw distance increases with the increase in coal quantity, and the throw distance with the volume of CGOH is more than $300 \mathrm{~m}^{3}$ which is obviously greater than that with the volume of CGOH less than $20 \mathrm{~m}^{3}$. (2) When the volume of CGOH is

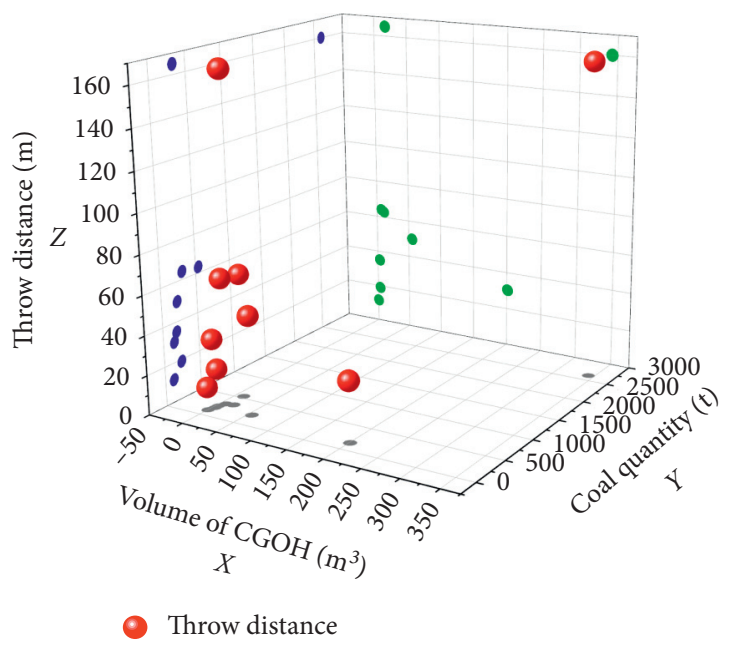

FIGURE 16: 3D scatter diagram of CGOH volume, coal quantity, and throw distance and its projection on three planes (XYZ gridding).

between $20 \sim 300 \mathrm{~m}^{3}$, the throw distance increases rapidly with the increase in coal quantity, then decreases, and finally, increases slowly. 


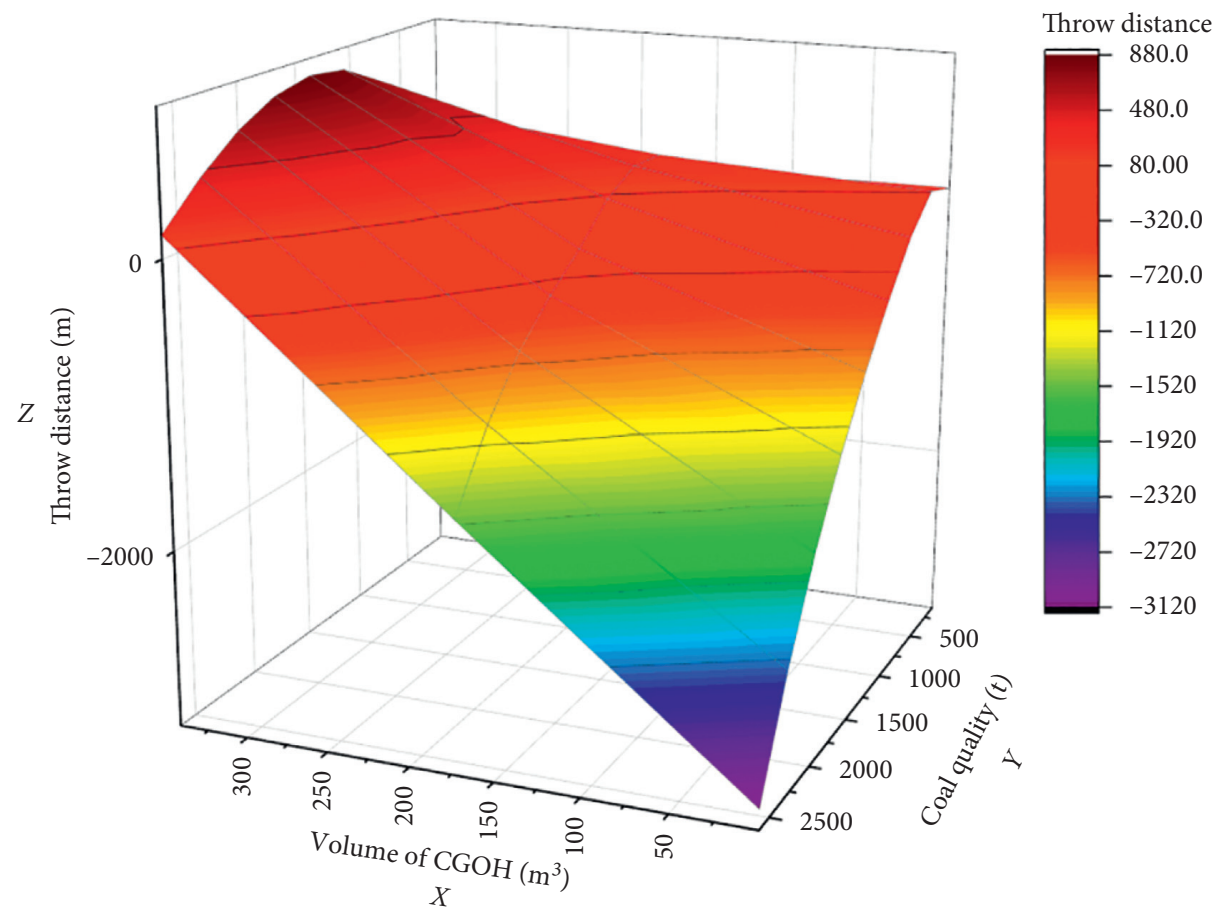

Figure 17: 3D colormap surface of CGOH parameters.

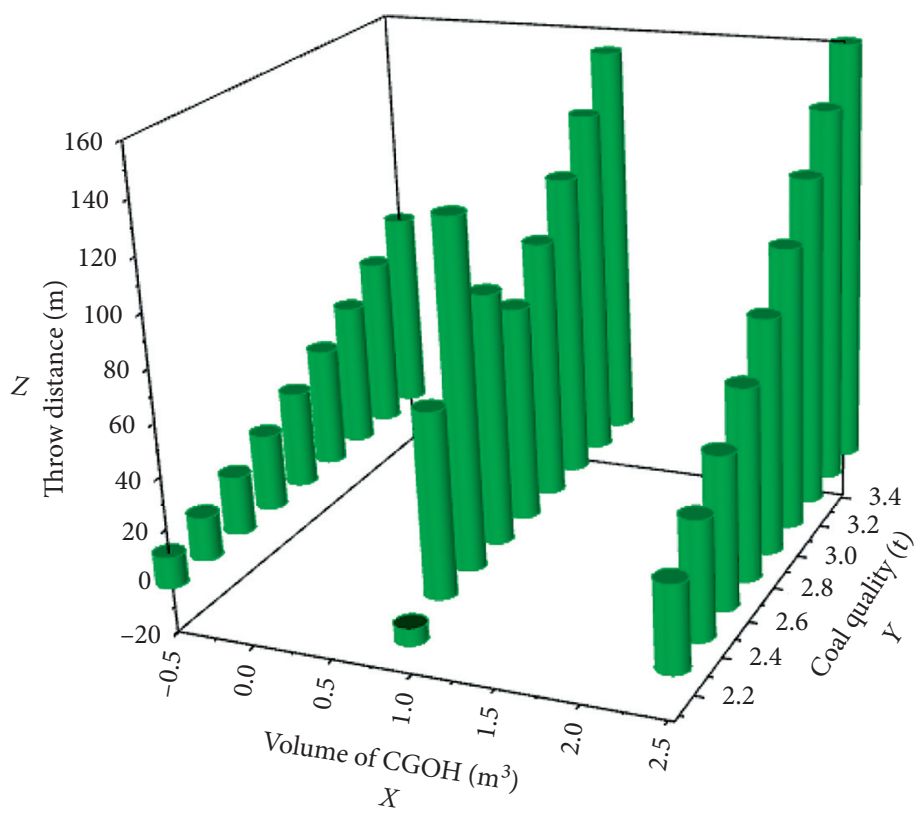

FIgURE 18: 3D bars of CGOH parameters ( $X Y Z$ log gridding).

As shown in Figures 19-21 and 23, the nonlinear fitting curve Gauss2D (mesh surface, degree of fit 95.53\%) and Extreme Cum (mesh surface, fitting degree 95.298\%) was used to fit the 3D colormap surface of $\mathrm{CGOH}$ parameters, and it was found that the $3 \mathrm{D}$ colormap surface of $\mathrm{CGOH}$ parameters was closer to a part of the two-dimensional Gaussian function (i.e., Gauss 2D) graph, and the two-dimensional Gaussian function is shown in (10), so CGOH volume, coal amount, and throw distance satisfied equation (11). 


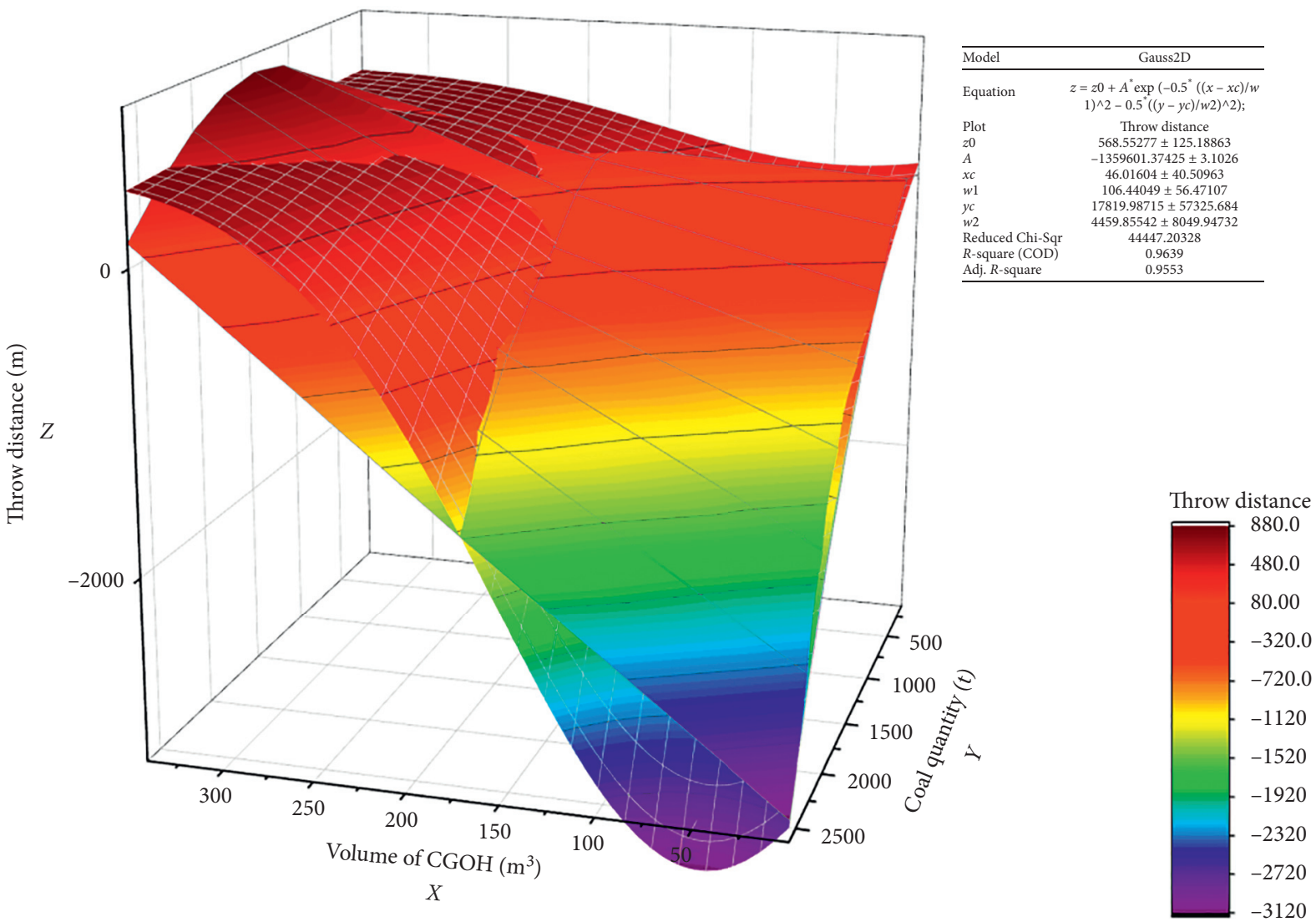

FIGURE 19: 3D color mapping surface of hole parameters and its nonlinear surface fit (Gauss2D).

$$
\begin{aligned}
& Z=Z_{0}+A * \operatorname{Exp}\left\{-\frac{1}{2}\left(\frac{x-x_{c}}{W_{1}}\right)^{2}-\frac{1}{2}\left(\frac{y-y_{c}}{W_{2}}\right)^{2}\right\} \\
& d=d_{0}+A * \operatorname{Exp}\left\{-\frac{1}{2}\left(\frac{v-v_{c}}{W_{1}}\right)^{2}-\frac{1}{2}\left(\frac{m-m_{c}}{W_{2}}\right)^{2}\right\} .
\end{aligned}
$$

\subsection{Application of the CGOH Parameter Equation}

2.4.1. Stagnation Point and Inflection Point in the CGOH Parameters Equation. The derivation of the $\mathrm{CGOH}$ parameter equation is shown in (12), and the solution is shown in (13) when the first derivative is zero. At the same time, the change in throw distance $Y$ in the definition domain of calculated density $X$ of the hole is obtained, which increases monotonically on the top and decreases at a single point on the top. See (14) for details.

$$
\begin{aligned}
& y^{\prime}=C(1-D x) e^{-D x}, \\
& \left\{\begin{array}{l}
y^{\prime}=0, \\
x=\frac{1}{D},
\end{array}\right. \\
& \left\{\begin{array}{l}
x \in\left(0, \frac{1}{D}\right], \quad y^{\prime} \geq 0, \\
x \in\left(\frac{1}{D},+\infty\right), \quad y^{\prime}<0 .
\end{array}\right.
\end{aligned}
$$

The second derivative of (12) is derived again and is shown in (15). When the second derivative is zero, the solution is (16). At the same time, the concavity and convexity of throw distance $Y$ in the domain $(1 / D,+\infty)$ of hole calculation density $X$ are obtained, as shown in (17). The curve of the outbursting hole parameters is still monotonically decreasing in $(1 / D,+\infty)$, concave in $(1 / D, 2 / D)$, and convex in $(2 / D,+\infty)$. See Figure 24 for details. 


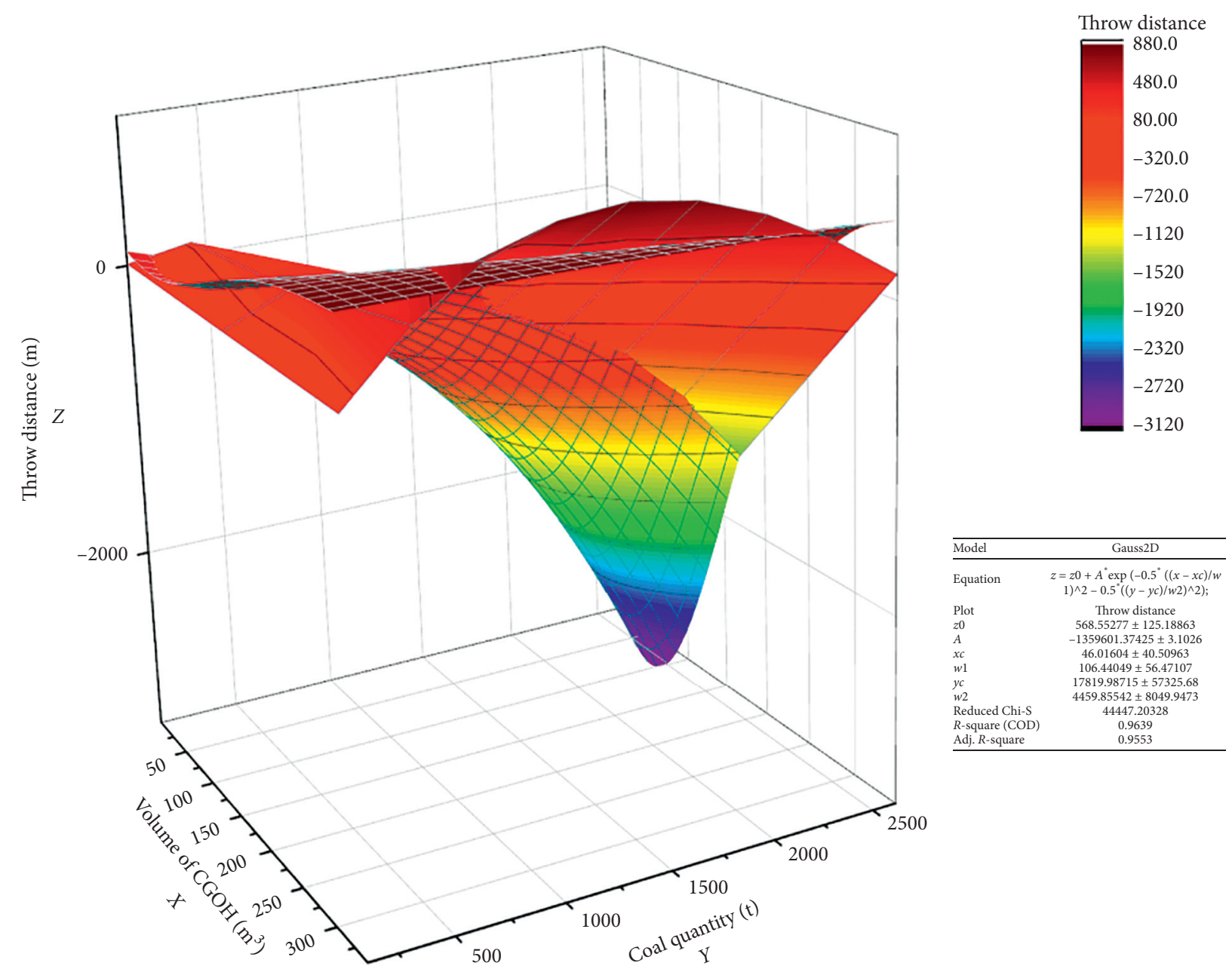

FIGURE 20: 3D color surface map of hole parameters and its nonlinear surface fit (Gauss2D).

$y^{\prime \prime}=C D(D x-2) e^{-D x}$

$\left\{\begin{array}{l}y^{\prime \prime}=0 \\ x=\frac{2}{D}\end{array}\right.$

$\begin{cases}x \in\left(\frac{1}{D}, \frac{2}{D}\right], & \text { Concave function, } \\ x \in\left(\frac{2}{D},+\infty\right), & \text { Convex function. }\end{cases}$

$$
y=\frac{a}{1+b e^{-k x}} \Longleftrightarrow v=\frac{a}{1+b e^{-k p}} .
$$

Therefore, there are stagnation points in the calculated density of holes. The stagnation point of the calculated density of holes corresponding to the maximum throw distance is $x=(1 / D)$, the inflection point of the calculated density of holes is $x=(2 / D)$, and the abscissa of the inflection point is twice that of the abscissa of the stagnation point.

2.4.2. Conversion Path from CGO to Coal and Gas Pour Out or Press Out. For the $\mathrm{CGOH}$ parameter equation
$y=C \cdot x \cdot e^{-D \cdot x}$, from the mathematical point of view, when the calculated density of $\mathrm{CGOH}$ approaches infinity, the throw distance tends toward zero, from which the following conclusions are drawn:

(1) When the calculated density of CGOH approaches infinity, the CGO turns into the extrusion or dumping of coal and gas. In other words, an increase in the density of the $\mathrm{CGOH}$ is the precondition or transformation path from CGO to coal and pour out or press out.

(2) The inflection point is the critical point for a CGO to turn into coal and gas pour out or press out.

(3) $(0,2 / D]$ is the calculated density of $\mathrm{CGOH}$, which is gradually converted to coal and gas pour out for $(2 / D,+\infty)$. With a further increase in the calculated density, it is finally converted to coal and gas press out.

\section{Relationship between Gas Pressure and the CGOH Parameter Equation}

According to the experiment conducted by M. Cheng [32], the gas pressure and $\mathrm{CGOH}$ parameters are shown in 

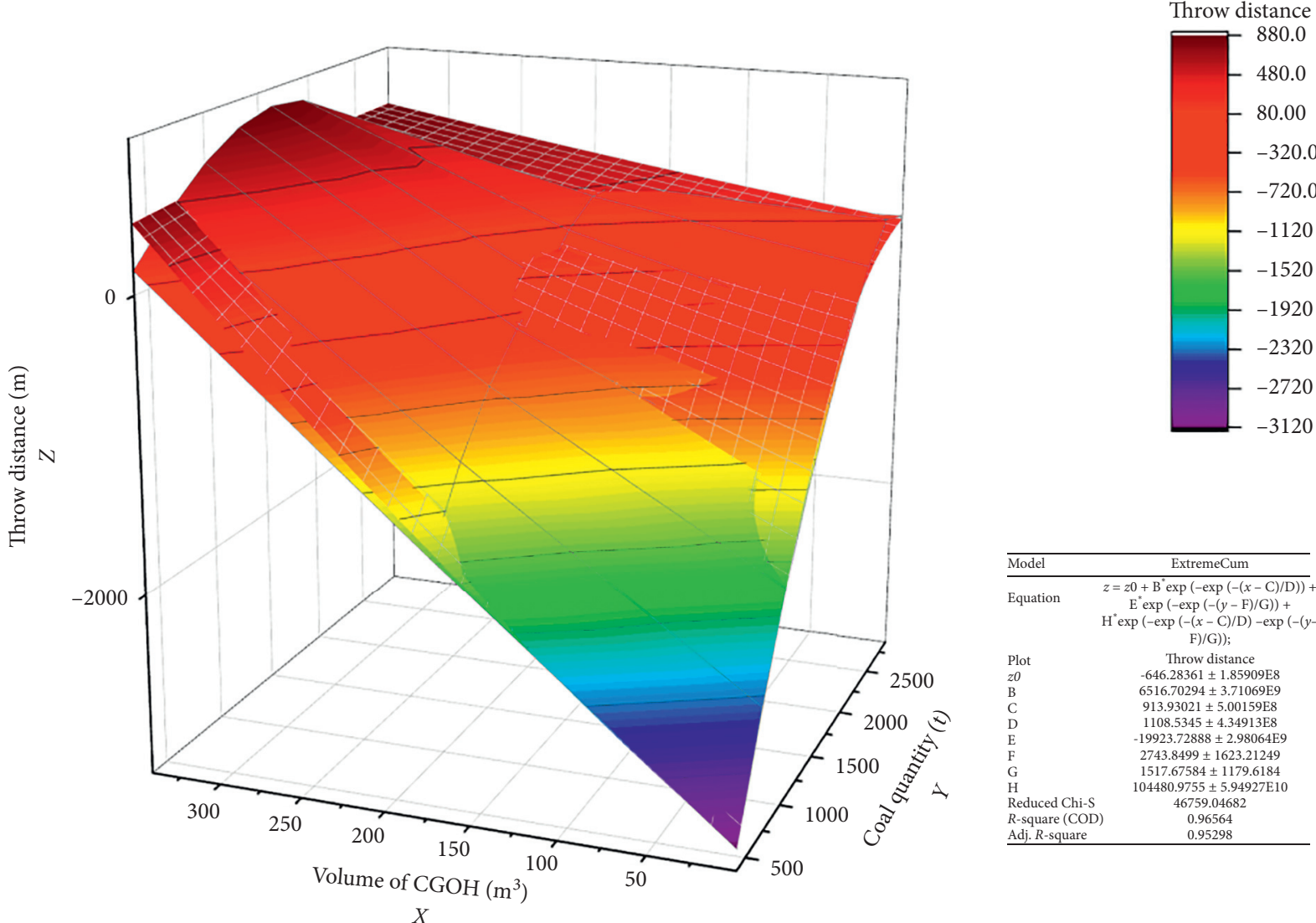

FIgURE 21: 3D colormap surface of $\mathrm{CGOH}$ parameters and its nonlinear surface fit (Extreme Cum).

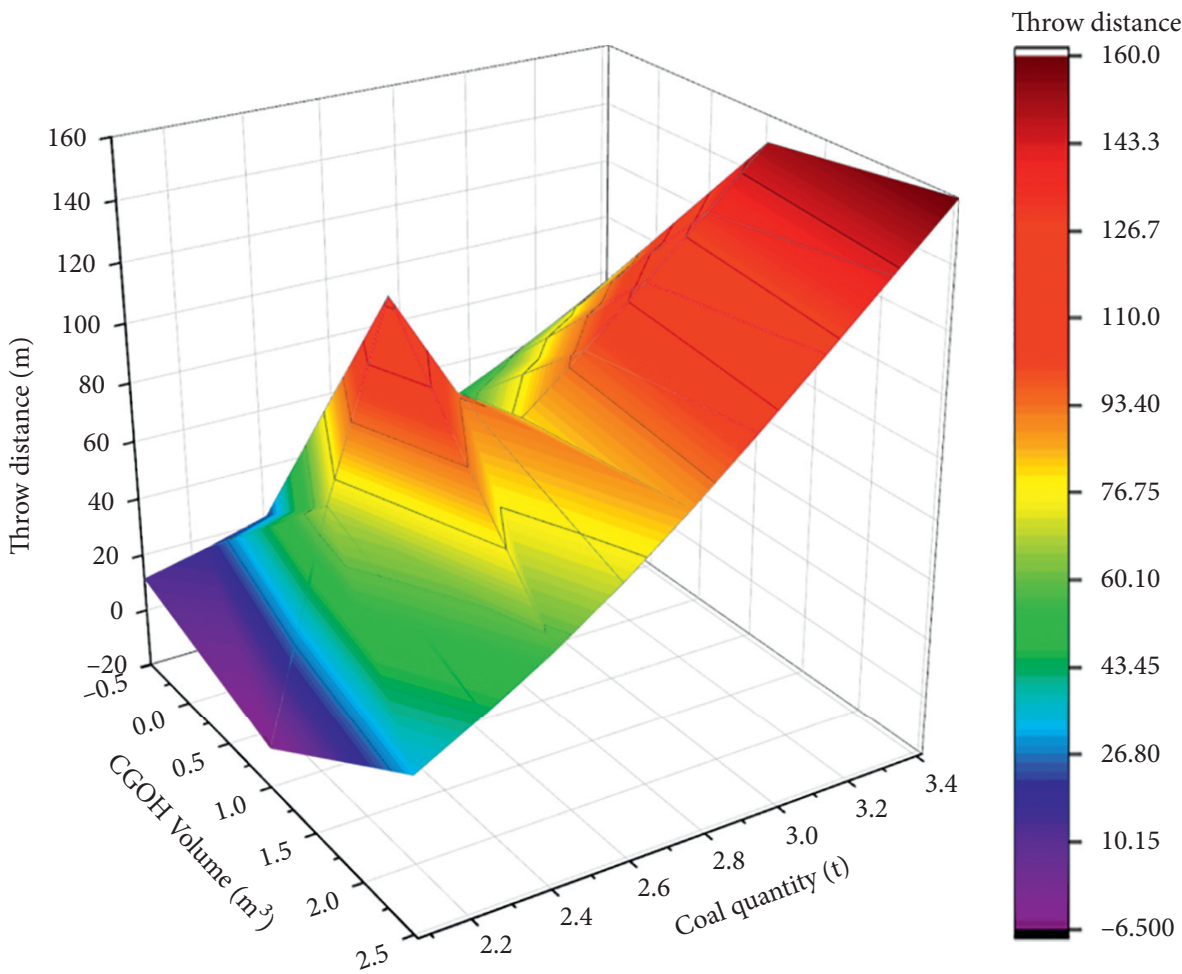

FIGURE 22: 3D color surface map of $\mathrm{CGOH}$ parameters (XYZ log gridding). 


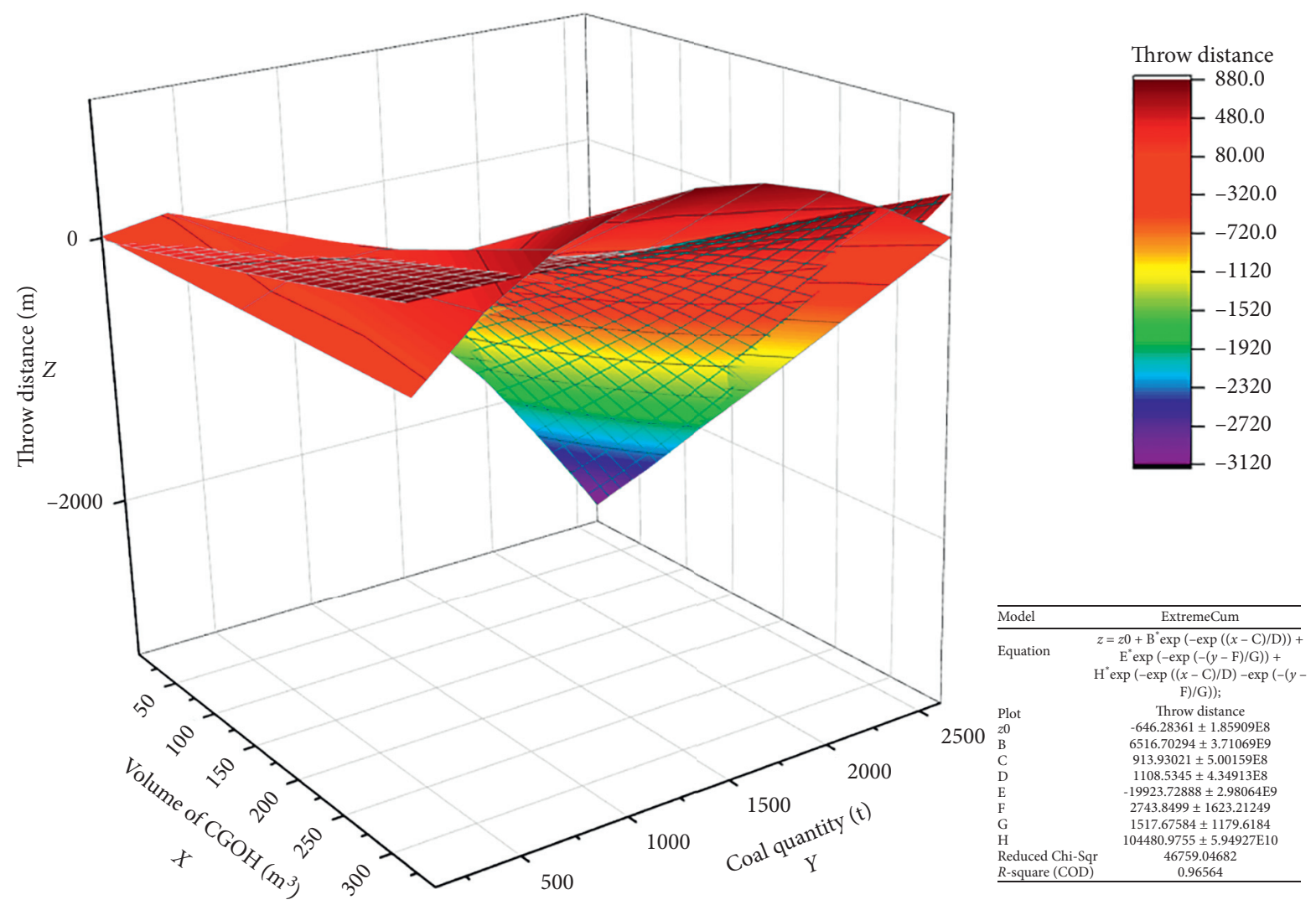

FIGURE 23: 3D colormap surface of $\mathrm{CGOH}$ parameters and its nonlinear surface fit (Extreme Cum).

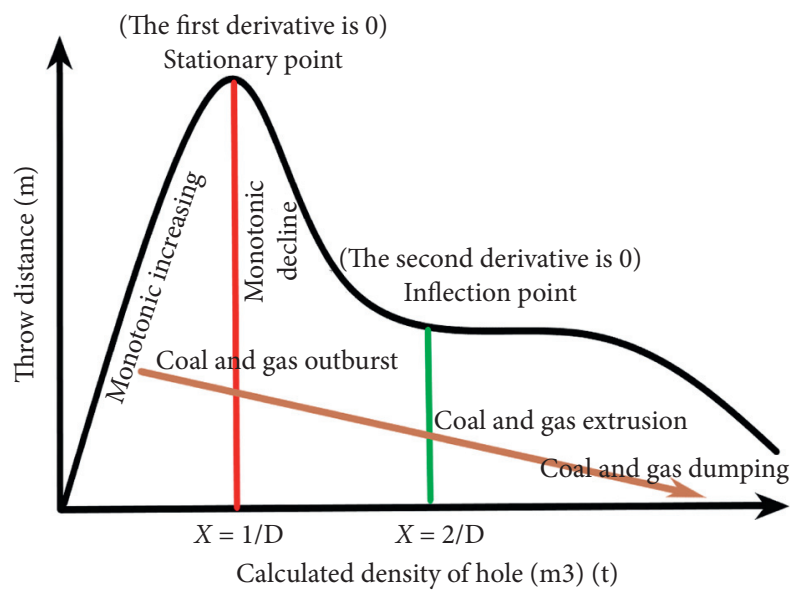

FIgURE 24: Conversion path of coal and gas outburst to pour out or press out.

Table 7. Different functions are used to fit the gas pressure and $\mathrm{CGOH}$ volume. Four functions are appropriate, which are Lognormal, Boltzmann, Slogistic1, and Slogistic3, respectively. Slogistic1 and Slogistic3 are the best fitting curves, especially Slogistic3 $(x, a, b, k)$, as shown in Figures 25-28 and (18). 
TABLE 7: Experimental statistics of gas pressure and volume of $\mathrm{CGOH}$.

\begin{tabular}{|c|c|c|c|c|c|}
\hline Number of tests & 1 & 2 & 3 & 4 & 5 \\
\hline Diameter of outburst opening/mm & 60 & 60 & 60 & 60 & 60 \\
\hline Experimental coal consumption $/ \mathrm{kg}$ & 90.703 & 89.277 & 91.064 & 91.55 & 90.654 \\
\hline Briquetting pressure of experimental coal/Mpa & 4 & 4 & 4 & 4 & 4 \\
\hline Vertical stress/Mpa & 4 & 4 & 4 & 4 & 4 \\
\hline Horizontal stress/Mpa & 2.4 & 2.4 & 2.4 & 2.4 & 2.4 \\
\hline Gas pressure/Mpa & 0.5 & 0.75 & 1 & 1.25 & 1.5 \\
\hline Coal quantity of $\mathrm{CGOH} / \mathrm{kg}$ & 0 & 4.387 & 19.581 & 8.226 & 21.846 \\
\hline Length of $\mathrm{CGOH} / \mathrm{mm}$ & 0 & 165 & 256 & 279 & 353 \\
\hline Width of $\mathrm{CGOH} / \mathrm{mm}$ & 0 & 119 & 232 & 172 & 219 \\
\hline Height of $\mathrm{CGOH} / \mathrm{mm}$ & 0 & 193 & 236 & 265 & 197 \\
\hline Volume of $\mathrm{CGOH} / \mathrm{m}^{3}$ & 0 & 0.001984206 & 0.00733902839616853 & 0.006658511 & 0.007974136 \\
\hline
\end{tabular}

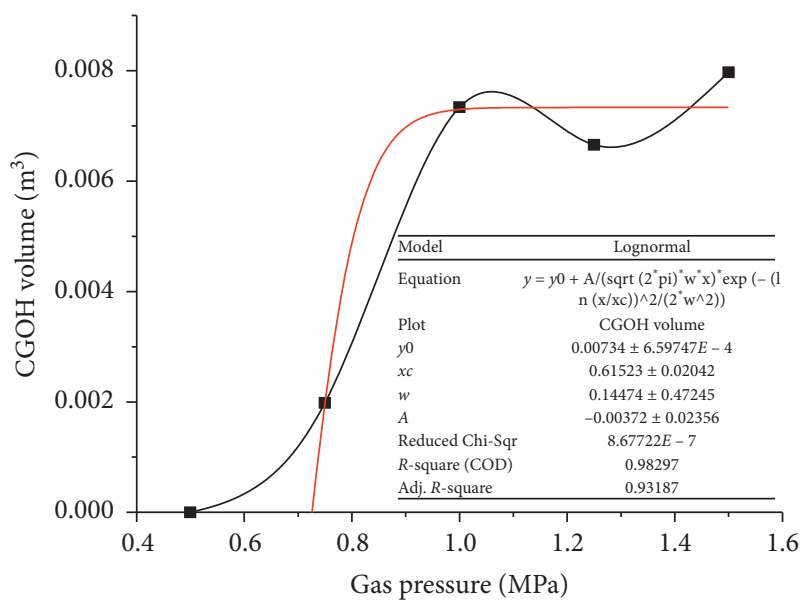

Figure 25: Fitting gas pressure and volume with the lognormal function.

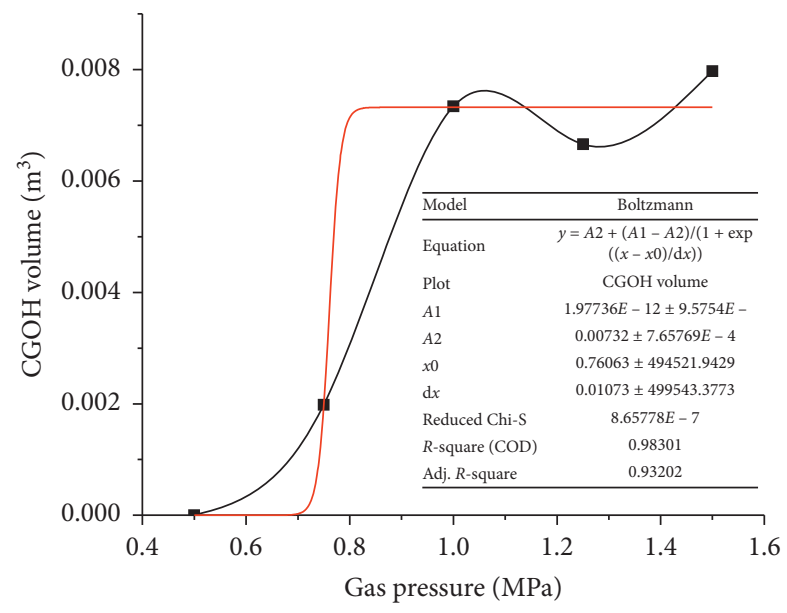

FIgURE 26: Fitting gas pressure and volume with the Boltzmann function. 


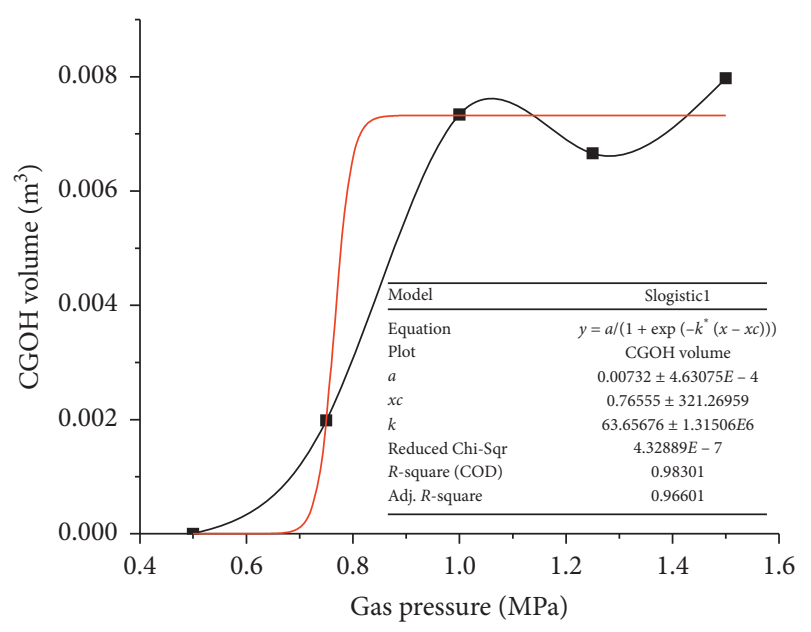

FIGURE 27: Fitting gas pressure and volume with the Slogistic1 function.

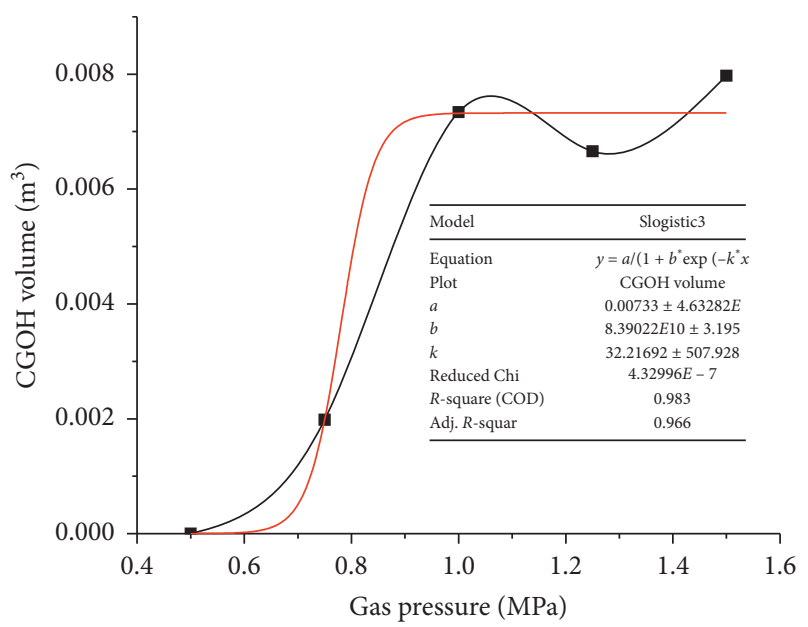

FIGURE 28: Fitting gas pressure and volume curve with the Slogistic3 function.

$$
\begin{aligned}
& \left\{\begin{array}{l}
d=C \frac{m}{v} e^{-D(m / v)}, \\
v=\frac{a}{1+b e^{-k p}},
\end{array}\right. \\
& \left\{\begin{array}{l}
d=d_{0}+A e^{-(1 / 2)\left(v-v_{c} / w_{1}\right)^{2}-(1 / 2)\left(m-m_{c} / w_{2}\right)^{2}}, \\
v=\frac{a}{1+b e^{-k p}},
\end{array}\right. \\
& d=\frac{m C\left(1+b e^{-k p}\right)}{a} e^{\left(-m D\left(1+b e^{-k p}\right) / a\right)}, \\
& d=d_{0}+A e^{-(1 / 2)\left(\left(a / 1+b e^{-k p}\right)-v_{c} / w_{1}\right)^{2}-(1 / 2)\left(m-m_{c} / w_{2}\right)^{2} .} .
\end{aligned}
$$

It shows the following rules: (1) There is an initial value of gas pressure $P_{0}$ in CGO. When the gas pressure $P$ is less than $P_{0}$, no CGO occurs; when the gas pressure $P$ is greater than $P_{0}$, CGO begins. (2) The CGOH volume increases with the increase in gas pressure, but there is an upper limit of $\mathrm{CGOH}$ volume. (3) The relationship between gas pressure and $\mathrm{CGOH}$ volume satisfies the logistic function, which is a common S-shaped curve. At the beginning, $\mathrm{CGOH}$ volume increases exponentially with the increase in gas pressure. Then, the CGOH volume increases slowly with the increase of gas pressure and finally approaches the upper limit of volume.

We combine (9) and (18) to get (19), combine (11) and (18) to get (20), and finally, get (21) and (22).

The essence of (20) is the same as that of (22), and the most interesting ones are (20) and (22), and (23) is obtained by modifying (20).

$$
\left\{\begin{array}{l}
d=d_{0}+\frac{A}{e^{(1 / 2)\left(v-v_{c} / w_{1}\right)^{2}+(1 / 2)\left(m-m_{c} / w_{2}\right)^{2}}}, \\
v=\frac{a}{1+b e^{-k p}} .
\end{array}\right.
$$

Obviously, there are two special values in (23), $v_{c}$ and $m_{c}$. When $v$ and $m$ (from the left or right) infinitely approach $v_{c}$ 
and $m_{c}, d$ gets the maximum, when $v$ and $m$ (from the left or right) are far away from $v_{c}$ and $m_{c}, d$ gets the minimum, and because $v$ is consistent with the variation trend of gas pressure, it is deduced that there is a $p_{c}$, and when $p$ (from the left or right) infinitely approaches $p_{c}$, the throw distance increases. When $p$ (to the left or right) is far away from $p_{c}$, the throw distance decreases.

Therefore, the process of CGO is discussed as follows: when original coal seam is disturbed by outside forces, the gas adsorbed in the coal body begins to desorb, along with the gas pressure rising. When the gas pressure is less than $P_{0}$, the CGO does not occur. When the gas pressure exceeds $P_{0}$, CGO begins to occur. The throw distance reaches the maximum when gas pressure approaches or reaches $p_{c}$, and then, although gas pressure increases further, the throw distance begins to decrease.

The reason is that when the gas pressure is greater than $p_{c}$, more coal is thrown out by gas flow in unit time, and the increased gas pressure is not enough to make these newly increased coal be thrown out for a longer distance, which is reflected in the continuous increase of calculated density and the continuous decrease of throw distance.

When the increase of gas pressure is larger enough and faster enough, because the coal body has not gathered more outburst energy, the gas pressure has torn the coal body, causing the coal and gas to be poured out or pressed out. Although a large amount of gas will be released in the process, there will not be a large number of coal bodies thrown out. It can also deduced from (23) that when $m$ is large enough, due to the upper limit value of $v$, the calculated density tends to infinity and $d$ is minimal. When $m$ and $v$ are close to $m_{c}$ and $v_{c}, d$ is maximal.

\section{Conclusions}

The following conclusions can be drawn based on the study of the parameters of outburst holes:

(1) There is a linear correlation (positive correlation) between the CGO coal quantity and throw distance, but the 3D diagram further shows the complex relationship between them. In the shallow and deep buried depth, with the increase of coal quantity, throw distance increases continuously and decreases after reaching the maximum throw out distance. At the same time, throw distance of shallow buried depth is obviously greater than that of deep buried depth. In the middle buried depth, throw distance increases with the increase of coal quantity; the distance first increases, then decreases, and then, increases to the maximum value and then decreases.

(2) The CGOH parameters (coal quantity, CGOH volume, and throw distance) are nonlinearly correlated and satisfy the following equation:

$$
d=C \cdot \frac{m}{v} \cdot e^{-D \cdot(m / v)},
$$

(3) There are stagnation and inflection points in the curve of the CGO hole parameters, and the inflection point is the critical point for coal and gas outburst. An increase in the calculated density of holes is the conversion path from coal and gas outburst to coal and gas extrusion or dumping.

(4) The CGOH parameter equation further deduces the equation of gas pressure, coal quantity, and throw distance, which meets the following equation:

$$
\begin{aligned}
d= & \frac{m C\left(1+b e^{-k p}\right)}{a} e^{\left(-m D\left(1+b e^{-k p}\right) / a\right)} \text { or } d=d_{0} \\
& +A e^{-1 / 2\left(\left(a / 1+b e^{-k p}\right)-v_{c} / w_{1}\right)^{2}-1 / 2\left(m-m_{c} / w_{2}\right)^{2}} .
\end{aligned}
$$

(5) There are three special data, i.e., $v_{c}, m_{c}$, and $p_{c}$. At the same time, the $\mathrm{CGOH}$ volume and gas pressure meet the Logistic function, and there is an upper limit for the $\mathrm{CGOH}$ volume.

\section{Data Availability}

The data used to support the findings of this study are available from the corresponding author upon request.

\section{Conflicts of Interest}

The authors declare no conflicts of interest regarding the publication of this paper.

\section{Acknowledgments}

This research was financially supported by the National Natural Science Foundation of China (51674102 and 51874121), NSFC-Key Projects Supported by Henan United Fund (U1904210), Key Scientific and Technological Research Plan of Henan Province, China (182102310002), and the funding for Special Research Funds for Colleges and University in Henan Province, China (NSFRF180104).

\section{References}

[1] B. Shi, Q. Yu, and K. Wang, "Experimental study on the dynamic evolution law of the permeability coefficient of the overlying coal seam mined by the remote protective layer," Journal of Rock Mechaincs and Engineering, vol. 25, no. 9, pp. 1917-1921, 2006.

[2] C. Xin, F. Du, K. Wang, C. Xu, S. Huang, and J. Shen, "Damage evolution analysis and gas-solid coupling model for coal containing gas," Geomechanics and Geophysics for GeoEnergy and Geo-Resources, vol. 7, no. 7, 2021.

[3] S. Zhou, "Theological hypothesis of coal and gas outburst mechanism," Journal of China University of Mining and Technology, vol. 19, no. 2, pp. 1-8, 1990.

[4] B. Liang and M. Zhang, "Solid fluid coupling instability theory of coal and gas outburst," Journal of Coal, vol. 20, no. 5, pp. 492-496, 1995.

[5] K. Wang and F. Du, "Coal-gas compound dynamic disasters in China: a review," Process Safety and Environmental Protection, vol. 133, pp. 1-17, 2020.

[6] F. Du and K. Wang, "Unstable failure of gas-bearing coal-rock combination bodies: insights from physical experiments and 
numerical simulations," Process Safety and Environmental Protection, vol. 129, pp. 264-279, 2019.

[7] J. Tang, J. Lv, Y. Pan, L. Yang, and Y. Wang, "Study on the relationship between gas pressure and outburst parameters based on jet theory," Journal of Natural Disasters, vol. 23, no. 2, pp. 232-238, 2014.

[8] D. Guo and D. Han, "Study on risk slip mechanism of coal and gas outburst," Journal of Coal, vol. 28, no. 6, pp. 598-602, 2003.

[9] Z. Ma and Q. Yu, "Preliminary study on the out of control outburst mechanism of coal ang gas pressured dispersion," Journal of Coal, vol. 31, no. 3, pp. 329-333.

[10] F. Du, K. Wang, X. Zhang, C. Xin, L. Shu, and G. Wang, "Experimental study of coal-gas outburst: insights from coalrock structure, gas pressure and adsorptivity," Natural Resources Research, vol. 29, no. 4, pp. 2481-2493, 2020.

[11] C. Cai, "Experimental study on 3-D simulation of coal and gas outbursts," Journal of China Coal Society, vol. 1, pp. 66-69, 2004.

[12] H. Yan and T. Xu, "Laboratory experiments and numerical simulation on coal and gas outbursts," China Safety Society, vol. 9, pp. 37-42, 2008.

[13] G. Yin, H. Zhao, J. Xu, and W. Wang, "Experimental study of simulation of coal and gas outburst," China of Rock Mechanical Engineering, vol. 28, pp. 1674-1680, 2009.

[14] G. Yin, X. Li, C. Jiang, G. Li, and B. Cai, "Simulation experiments of coal and gas delay outburst in rock cross-cut coal uncovering," Journal of University Science. Technology Beijing, vol. 32, pp. 827-832, 2010.

[15] J. Xu, D. Liu, S. Peng, W. Zhou, and M. Cheng, "Coal and gas outburst analogous test under the different diameter of exposed coal seam surface," Journal of China Coal Society, vol. 38, pp. 9-14, 2013.

[16] W. Wang, Y. Tao, J. Xu, and S. Peng, "Simulation of coal and gas outburst with different gas pressure," Journal of China Chongqing University, vol. 33, pp. 80-86, 2010.

[17] J. Sobczyk, "The influence of sorption processes on gas stresses leading to the coal and gas outburst in the laboratory conditions," Fuel, vol. 90, no. 3, pp. 1018-1023, 2011.

[18] R. Yuan and H. Li, "Development and application of simulation test apparatus for gassy coal dynamic failure," Journal of China Coal Society, vol. 38, pp. 117-123, 2013.

[19] C. Guo, X. Xian, W. Yao, and Y. Jiang, "Study on the relationship between coal and rock fracture failure area and coal and gas outburst holes," Journal of China University of Mining and Technology, vol. 39, no. 6, pp. 802-807, 2010.

[20] G. Wang, M. Wu, H. Wang, Q. Huang, and Y. Zhong, "Sensitivity analysis of influencing factors of coal and gas outburst based on energy balance model," Journal of Rock Mechanics and Engineering, vol. 34, no. 2, pp. 238-248, 2015.

[21] S. Liu, X. Li, D. Wang, M. Wu, G. Yin, and M. Li, "Mechanical and acoustic emission characteristics of coal at temperature impact," Natural Resources Research, vol. 29, no. 3, pp. 1755-1772, 2020.

[22] X. Li, Z. Cao, and Y. Xu, "Characteristics and trends of coal mine safety development," Energy Sources, Part A: Recovery, Utilization, and Environmental Effects, 2020.

[23] J. Xu, J. Geng, S. Peng, M. Yuan, C. Zhang, and X. Luo, "Experimental study on pulsating development process of coal and gas outburst," Journal of China University of Mining and Technology, vol. 47, no. 1, pp. 145-154, 2018.

[24] N. V. Gorbacheva and B. K. Sovacool, "Pain without gain? Reviewing the risks and rewards of investing in Russian coalfired electricity," Applied Energy, vol. 154, pp. 970-986, 2015.
[25] D. P. Tripathy and C. Kumar Ala, "Identification of safety hazards in Indian underground coal mines," Journal of Sustainable Mining, vol. 17, no. 4, pp. 173-175, 2018.

[26] D. J. Black, "Review of coal and gas outburst in Australian underground coal mines," International Journal of Mining Science and Technology, vol. 29, no. 6, pp. 815-824, 2019.

[27] K. Nilufer and O. Mustafa, "Application of structural equation modelling to evaluate coal and gas outbursts," Tunnelling and Underground Space Technology, vol. 88, pp. 63-72, 2019.

[28] R. Dmytro and S. Valerity, "A mathematical model of gas flow during coal outburst initiation," International Journal of Mining Science and Technology, vol. 29, no. 5, pp. 791-796, 2019.

[29] G. Wen, H. Sun, J. Cao et al., "Simulation experiment system of deep well coal rock gas dynamic disaste," Acta Coalae Sinica, vol. 45, no. 1, pp. 223-231, 2020.

[30] L. Wu, F. Wang, and Y. Yang, "Study and application of gas flow equation in coal seam," Journal of Mining and Safety Engineering, vol. 33, no. 5, pp. 951-956, 2016.

[31] J. Tang, "Nonlinear curve fitting based on MATLAB," Computer and Modernization, vol. 6, pp. 15-19, 2008.

[32] M. Cheng, "Experimental study on coal permeability and coal and gas outburst process simulation," Chongqing University, Chongqing, China, Thesis, 2008. 